\title{
Comparison of three generic quality-of-life metrics in peripheral arterial disease patients undergoing conservative and invasive treatments
}

\author{
Svenja Petersohn ${ }^{1,2} \circledast$ Bram L. T. Ramaekers ${ }^{1,2} \cdot$ Renske H. Olie ${ }^{3,4} \cdot$ Arina J. ten Cate-Hoek $^{3,4}$. \\ Jan-Willem H. C. Daemen ${ }^{5}$ Hugo ten Cate ${ }^{3,4} \cdot$ Manuela A. Joore $^{1,2}$
}

Accepted: 12 March 2019 / Published online: 30 March 2019

(c) The Author(s) 2019

\begin{abstract}
Purpose To determine the effect of revascularisation for peripheral arterial disease (PAD) on QoL in the first and second year following diagnosis, to compare the effect depicted by Short Form Six Dimensions (SF-6D) and EuroQoL five Dimensions (EQ-5D) utilities, and Visual Analogue Scale (VAS) scores and to analyse heterogeneity in treatment response.

Methods Longitudinal data from 229 PAD patients were obtained in an observational study in southern Netherlands. Utility scores were calculated with the international (SF-6D) and Dutch (EQ-5D) tariffs. We analysed treatment effect at years 1 and 2 through propensity score-matched ANCOVAs. Thereby, we estimated the marginal means (EMMs) of revascularisation and conservative treatment, and identified covariates of revascularisation effect.

Results A year after diagnosis, 70 patients had been revascularised; the EMMs of revascularisation were $0.038,0.077$ and 0.019 for SF-6D, EQ-5D and VAS, respectively (always in this order). For conservative treatment these were $-0.017,0.038$ and 0.021. At 2-year follow-up, the EMMs of revascularisation were $0.015,0.077$ and 0.027 , for conservative treatment these were $-0.020,0.013$ and -0.004 . Baseline QoL (and rest pain in year 2) were covariates of treatment effect.

Conclusions We measured positive effects of revascularisation and conservative treatment on QoL a year after diagnosis, the effect of revascularisation was sustained over 2 years. The magnitude of effect varied between the metrics and was largest for the EQ-5D, which may be most suitable for QoL measurement in PAD patients. Baseline QoL influenced revascularisation effect, in clinical practice this may inform expected QoL gain in individual patients.
\end{abstract}

Keywords Peripheral arterial disease $\cdot$ Peripheral revascularisation $\cdot$ Utility $\cdot$ EuroQol EQ-5D (EQ-5D) $\cdot$ SF-6D

Svenja Petersohn

svenja.petersohn@mumc.nl

1 Department of Clinical Epidemiology and Medical Technology Assessment (KEMTA), Maastricht University Medical Centre +, Maastricht, The Netherlands

2 School for Public Health and Primary Care (CAPHRI), Maastricht University, Maastricht, The Netherlands

3 Department of Biochemistry, Cardiovascular Research Institute Maastricht (CARIM), Maastricht University, Maastricht, The Netherlands

4 Department of Internal Medicine, Maastricht University Medical Centre +, Maastricht, The Netherlands

5 Department of Vascular surgery, Maastricht University Medical Centre +, Maastricht, The Netherlands

\section{Introduction}

Peripheral arterial disease (PAD) is a chronic disease, characterised by the atherosclerotic narrowing of the lower extremity arteries [1]. PAD prevalence is estimated to be $3-10 \%$ overall, and $15-20 \%$ in the population older than 70 [2]; these numbers seem to be increasing [3]. The disease spectrum ranges from asymptomatic PAD to limb and life-threatening acute leg ischemia [4]. Symptomatic PAD, characterised by exercise-induced occurrence of ischemic muscle pain, causes loss in quality of life (QoL) through reduced physical well-being, mobility, independence and capacity to handle everyday life [5]. Peripheral revascularisation, the open- or endovascular restoring of blood flow in the legs, (f.i. angioplasty, bypass surgery), is typically applied for acute limb ischemia or disease progression 
despite conservative treatment [2] to restore peripheral reperfusion and reduce the symptom burden.

Previous studies have shown a positive effect on QoL a year after revascularisation [6]; the long-term effects of revascularisation are less verified as progression of atherosclerosis can cause restenosis [7]. Studies showed that 6 months after revascularisation, mean EuroQoL five Dimensions (EQ-5D) utilities increased, then stagnated during the following year [8]; 4 years after revascularisation, pain was the only Nottingham health profile domain significantly improved [9]. This calls into question the sustainability of the effect of revascularisation on QoL.

Guidelines recommend revascularisation only in selected patients with mild to moderate disease [7]. This indicates that disease severity might be a covariate of revascularisation effect on QoL, and some patients might achieve more desirable results than others. This hypothesis is supported by studies showing that 1 year after revascularisation, a proportion of patients did not achieve the desired results: $24.4 \%, 30.8 \%$ and $21.0 \%$ of patients did not have improved SF-36 domain scores for physical function, pain or a relevant EQ-5D utility improvement, respectively [10, 11].

In the above-mentioned studies, different methods were used to generate preferences for QoL. The Short Form 36 Health Survey (SF-36) and EQ-5D are based on the valuation of hypothetical health states by members of the general public, i.e. general public preference, in contrast the Nottingham health profile uses the patient's self-perceived health state preference, i.e. patient preference. It is acknowledged that different methods to generate QoL estimates will measure different aspects of QoL and thus will result in similar but not identical estimates. Research on instruments using general public vs. patient preferences has shown that results can differ, with the general public valuing health worse than patients do [12]. These findings have been confirmed in the valuation of cardiovascular events [13]. All mentioned instruments are generic, i.e. not designed specifically for PAD patients but can be used in any patient population. Differences can also arise between two generic, general public-based instruments [14], and arguments for and against several generic instruments in PAD patients have been presented [15-18]. The review of Poku et al. [18] concludes that the evidence on the psychometric properties of QoL instruments in PAD patients was limited and did not allow for the detection of superiority of one instrument. The evidence focussed on construct validity and responsiveness and reported favourable results for both SF-6D and EQ-5D. The review of Dyer et al. [19] positively commented on the convergent validity and responsiveness of the EQ-5D in PAD patients but did not assess the SF-6D.

PAD treatment is not curative but targeted at relieving PAD symptoms. Consequently, sustainability of QoL gains after revascularisation and variability in the magnitude of gains by patient characteristics are relevant factors in clinical decision making. Beyond that, however, estimations of treatment effect on QoL directly affect the number of quality-adjusted life years attributable to that intervention, and thus play a key role in the evaluation of cost-effectiveness of PAD treatment. Differences between QoL instruments can influence costeffectiveness estimates, which can misinform policy decision and eventually can lead to the suboptimal use of healthcare. To address those issues, we (1) evaluated, 1 year after PAD diagnosis, the effect of revascularisation on QoL in terms of magnitude and influence of covariates, and compared these results between three QoL metrics, (2) evaluated, 2 years after PAD diagnosis, the sustainability of the effect of revascularisation in year one on QoL, in terms of magnitude and influence of covariates and compared these results between three QoL metrics. This paper presents estimates of treatment effect and offers recommendations for the choice of QoL metric.

\section{Methods}

\section{Study design}

This observational study was conducted between January 2009 and November 2013 in three Dutch hospitals. Approval was obtained at the Medical Ethical Committee (CMO) of the MUMC+. Medical history and QoL was documented in consecutive newly diagnosed PAD patients, who were followed up over 2 years with repeated QoL measurements and documentation of peripheral revascularisation interventions.

\section{Study population}

Patients referred to the vascular department for newly diagnosed PAD were eligible for participation. Inclusion criterion was an ankle brachial index (ABI; the ratio between systolic blood pressure in ankle and arm, measured at rest [20]) of $<0.9$ in any leg, measured in the hospital. Patients were included after signing informed consent. Exclusion criteria are listed in Appendix 2. Furthermore, patients were excluded from the analysis when none of the baseline and follow-up QoL instruments had been returned. To ensure homogeneity of time since revascularisation, patients were excluded when revascularisation took place less than 90 days before year 1 follow-up, this was based on medical expert opinion.

\section{Data collection}

For each patient, a case report form was created in an online database, containing patient characteristics, QoL and treatment. Patient characteristics were self-reported in an interview with a research nurse or study physician. At baseline, 1 and 2 years after study inclusion, patients filled in the SF-36 and the EQ-5D measurement instruments. By questionnaire, 
patients reported treatments received and cardiovascular events experienced during the previous year, 1 and 2 years after baseline (see Appendix 2 for a definition of cardiovascular events); these data were cross-checked with patient medical files for completeness. A research nurse telephoned the patient upon missing data or ambiguous answers.

\section{Patient characteristics and treatment}

A summary of patient characteristics tested as covariates of treatment effect, their definitions and specifications used in the analyses is given in Table 1. Patients received conservative treatment according to PAD guidelines [7]. This included lifestyle advice regarding smoking cessation and physical exercise, and pharmacotherapy focussed on controlling blood pressure and cholesterol levels. Patients were advised to do unsupervised exercise or received exercise therapy supervised by a physiotherapist. Invasive treatment was defined as peripheral revascularisation which entailed endovascular interventions (e.g. angioplasty with and without stent placement) and open surgery (e.g. atherectomy and endarterectomy, and bypass surgery). Revascularisations were considered relevant for this study when performed within 1 year of PAD diagnosis.

\section{Short Form 36 Health Survey based SF-6D}

The SF-36 is a well-known generic health-related qualityof-life (HR-QoL) metric that has been extensively tested in Dutch populations [25]. The SF-6D has been developed to estimate HR-QoL using ten of the thirty-six items of the SF-36 [26]. Four to six ordinal answers are offered per item, each answer matched with a preference weight to value the desirability of the answer. In the absence of a Dutch tariff, the UK tariff of the SF-6D was used. Combining the valued item responses, domain scores and an overall utility are calculated, each of them between 0.29 and 1.00 to indicate maximum disability to perfect health [25].

\section{EuroQoL five dimensions}

The EQ-5D is a generic QoL instrument. Since 2008, the 3-level version of the EQ-5D used in this study is the preferred QoL measure in economic evaluations conducted

Table 1 Names and definitions of patient characteristics

\begin{tabular}{|c|c|}
\hline Characteristic & Definition \\
\hline \multicolumn{2}{|l|}{ Disease severity } \\
\hline Fontaine stage & $\begin{array}{l}\text { PAD severity grading system [21] } \\
\text { Mild }=(\mathrm{I}) \text { asymptomatic, }(\mathrm{IIa}) \text { claudication at }>200 \mathrm{~m} \text { walking distance } \\
\text { Severe }=\text { (IIb) claudication at }<200 \mathrm{~m} \text { walking distance, (III) rest pain and (IV) necrosis or gangrene }\end{array}$ \\
\hline $\mathrm{ABI}$ & Lower ABI (left or right ankle blood pressure/higher brachial blood pressure) [22] \\
\hline Claudication distance & Distance walked in $\mathrm{m}$ to provoke claudication symptoms \\
\hline Rest pain & Patient-reported pain at rest \\
\hline Complaints in daily life & Patient-reported complaints during activities of daily life \\
\hline Progressive symptoms & Patient reported, within the past 6 months \\
\hline \multicolumn{2}{|l|}{ Demographics } \\
\hline Age & In years \\
\hline Gender & Male or female \\
\hline BMI & Body mass in kg divided by the square of the body height in $\mathrm{m}$ [23] \\
\hline Currently smoking & Patient-reported smoking status \\
\hline \multicolumn{2}{|l|}{ Comorbidities } \\
\hline Stroke & Diagnosis of stroke or transient ischemic attack $>6$ months ago \\
\hline Myocardial infarction & Diagnosis of acute myocardial infarction $>6$ months ago \\
\hline DM I & Diagnosis of insulin-dependent diabetes \\
\hline DM II & Diagnosis of non-insulin-dependent diabetes \\
\hline Hypertension & $\mathrm{BP}$ of $>140 / 90 \mathrm{mmHg}$ and treated with antihypertensive medication \\
\hline Hypercholesterolemia & Treatment with cholesterol-lowering drugs \\
\hline Elevated D-Dimer & $\begin{array}{l}\text { In patients } \leq 50 \text { years old: D-Dimer }>500 \mu \mathrm{g} / \mathrm{L} \\
\text { In patients }>50 \text { years: D-Dimer in } \mu \mathrm{g} / \mathrm{L}>\text { patient's age } * 10\end{array}$ \\
\hline Impaired kidney function & $\begin{array}{l}\text { Indicated by Modification of Diet in Renal Disease estimated glomerular filtration rate (MDRD). } \\
\text { Estimated from serum creatinine, age and gender } \\
\text { Cut-off: }<60 \mathrm{ml} / \mathrm{min} / 1.73 \mathrm{~m}^{2}[24]\end{array}$ \\
\hline Malignancies & Previous or current malignancies \\
\hline
\end{tabular}


for NICE in the United Kingdom [27]. In the Netherlands, this recommendation has been superseded in favour of the newer 5-level version of the EQ-5D in 2016 [28].The instrument consists of two metrics, the first being a selfclassification of health in five domains: mobility, self-care, usual activities, pain/discomfort and anxiety/depression. The respondent indicates if 'no problems', 'some problems' or 'severe problems' occur in each domain; the Dutch tariff of Lamers et al. [29] is used to value the response with a preference weight. All domains combined, a utility is created; the maximum utility of one indicates perfect health, a utility of zero indicates death and the minimum utility of -0.33 indicates conditions worse than death [30].

The second metric, the Visual Analogue Scale (VAS) is a psychometric response scale, recording the respondent's valuation of their overall health on a scale from 100 to 0 , representing best imaginable to poorest imaginable health [30]. The VAS represents a patient's preference for her own health state. For comparability purposes, VAS scores were divided by 100 to create a score between 1 and 0 .

\section{Missing data}

To prevent a loss of precision and the introduction of bias through the exclusion of patients with missing data, missing items of the quality-of-life instruments and baseline patient characteristics were replaced using multiple imputation [31]. Categorical items of the QoL instruments were imputed using dummy coding [32]. We set the number of imputations to 10 and performed sensitivity analysis comparing outcomes of the pooled imputed datasets to a complete case analysis (see Appendixes 1 and 4). Patients who died received a score of 0 in all following QoL measurements.

\section{Propensity score matching}

For each of the 10 imputed datasets, a propensity score (PS) was estimated using logistic regression of baseline patient data [33]. The propensity score was created by testing all baseline patient characteristic parameters for their ability to predict treatment assignment, selecting those parameters with the highest $\mathrm{C}$-statistics and adding parameters that remained unbalanced until the propensity score resulted in adequate covariate balance of baseline characteristics. On this score, each revascularised patient was matched (with replacement) with one conservatively treated patent using the nearest neighbour technique and a calliper of 0.2 [34]. Covariate balance after matching was assessed by comparison of patient characteristics in the treatment groups and by means of visual inspection of QQ plots and PS distributions in the original and matched groups [34]. PS-matched datasets are adjusted against confounding by indication of treatment, allowing outcomes of treatment groups to be compared. PS matching was performed in $\mathrm{R}$ version 3.3.3.

\section{Statistical analysis}

Characteristics of patients with complete and incomplete QoL measurements were compared using Bonferroni corrected $t$ tests and Chi-square tests [35]. Paired-samples $t$ test were used to compare baseline QoL scores of the three instruments. Scatterplots and Pearson correlations were used to explore the effect of time since revascularisation on QoL change at year 1 follow-up.

To explore covariates of treatment effect and compare QoL response in revascularised and conservatively treated patients, analysis of covariance (ANCOVA) was used in the matched cohort producing estimated marginal means (EMMs) of revascularisation and conservative treatment in a post hoc analysis. Patient characteristics described in Table 1 and their interaction terms with revascularisation were included into the models. A backwards deletion approach with the $P$ value set to 0.05 was used; all variables were tested for multi-collinearity, variables were excluded if variance inflation factor (VIF) $>1 /\left(1-\right.$ model $R^{2}$ ) [36]. Variables found significant in one of the three QoL metric's models were entered into the models of all metrics. The analysis was conducted on baseline to year 1 change and baseline to year 2 change, and the latter analysis excluded patients with revascularisations in the second year. Analysis results that could not be pooled across multiple imputation datasets were presented as ranges. Sensitivity analyses were performed by comparing EMMs to crude scores and by applying the ANCOVA models in:

1. the unmatched sample;

2. the unmatched sample, exclusively using patients without cardiovascular events during follow-up;

3. the unmatched sample, exclusively using complete cases;

4. a sample excluding patients revascularised in the second half of the first follow-up year.

All statistical analyses were conducted on SF-6D, EQ-5D and VAS for comparison, using IBM SPSS Statistics version 23.

\section{Results}

The study population consisted of 285 patients. After exclusion of 56 patients for completely missing QoL measurements, the population analysed consisted of 229 PAD patients (see Fig. 1 for patient flow). Between 16.6 and $42.4 \%$ of metrics were missing, the measurement time with the largest proportions of missing values was 1-year follow-up and the metric with the largest proportions of missingness was SF-6D (see Table 5 in Appendix 1). Patients with and without 
missing QoL scores showed few differences in baseline characteristics (see Table 6 in Appendix 1).

\section{Population characteristics}

Mean age at baseline was 66 years (SD 8.141), the cohort consisted of $64.6 \%$ males and $53.3 \%$ current smokers. Mean resting ABI was 0.72 (SD 0.188), the prevalence rates of Fontaine stages IIb, III and IV were $33.6 \%, 2.2 \%$ and $0.9 \%$, respectively (see Table 2 for more baseline patient characteristics). Mean baseline QoL was 0.689 (SE 0.009) measured by the SF-6D, 0.637 (SE 0.019) measured by the EQ-5D and 0.665 (SE 0.015) measured by the VAS. SF-6D and EQ-5D QoL were significantly different from one another, for further details on baseline QoL, see Tables 6 and 7, Figs. 2a and 5 in Appendix 1. At 1-year follow-up, 70 patients $(30.6 \%)$ had received revascularisation, and no relationship was detected between time since revascularisation and change in QoL at year 1. Eighteen patients (7.9\%) experienced a cardiovascular event in the first year and seventeen patients during the second year $(7.4 \%)$. Seventeen patients were revascularised in the second year $(7.4 \%)$.

\section{Revascularisation effect and heterogeneity in response during the first year}

The descriptive system of the EQ-5D revealed that QoL gains after revascularisation were driven by increasing proportions of patients reporting 'no problems' with pain/discomfort, mobility and usual activities (see Fig. 3 in Appendix 1). All SF-6D domain scores increased, the largest increases were observed in the domains physical functioning, role limitations physical and pain (see Fig. 4 in Appendix 1).

Propensity score matching resulted in improved covariate balance between revascularised and conservatively treated patients. The propensity score and overviews of covariate balance after matching are presented in Appendix 3. Therefore, matched data were used in the ANCOVA analyses. The ANCOVA model (Table 3) showed that baseline QoL is a covariate of QoL change after treatment. All other baseline patient characteristics (see Table 1 for characteristics) and treatment type were not significant covariates. The models indicated QoL gain after treatment was larger in patients with low baseline QoL.

Fig. 1 Patient flow

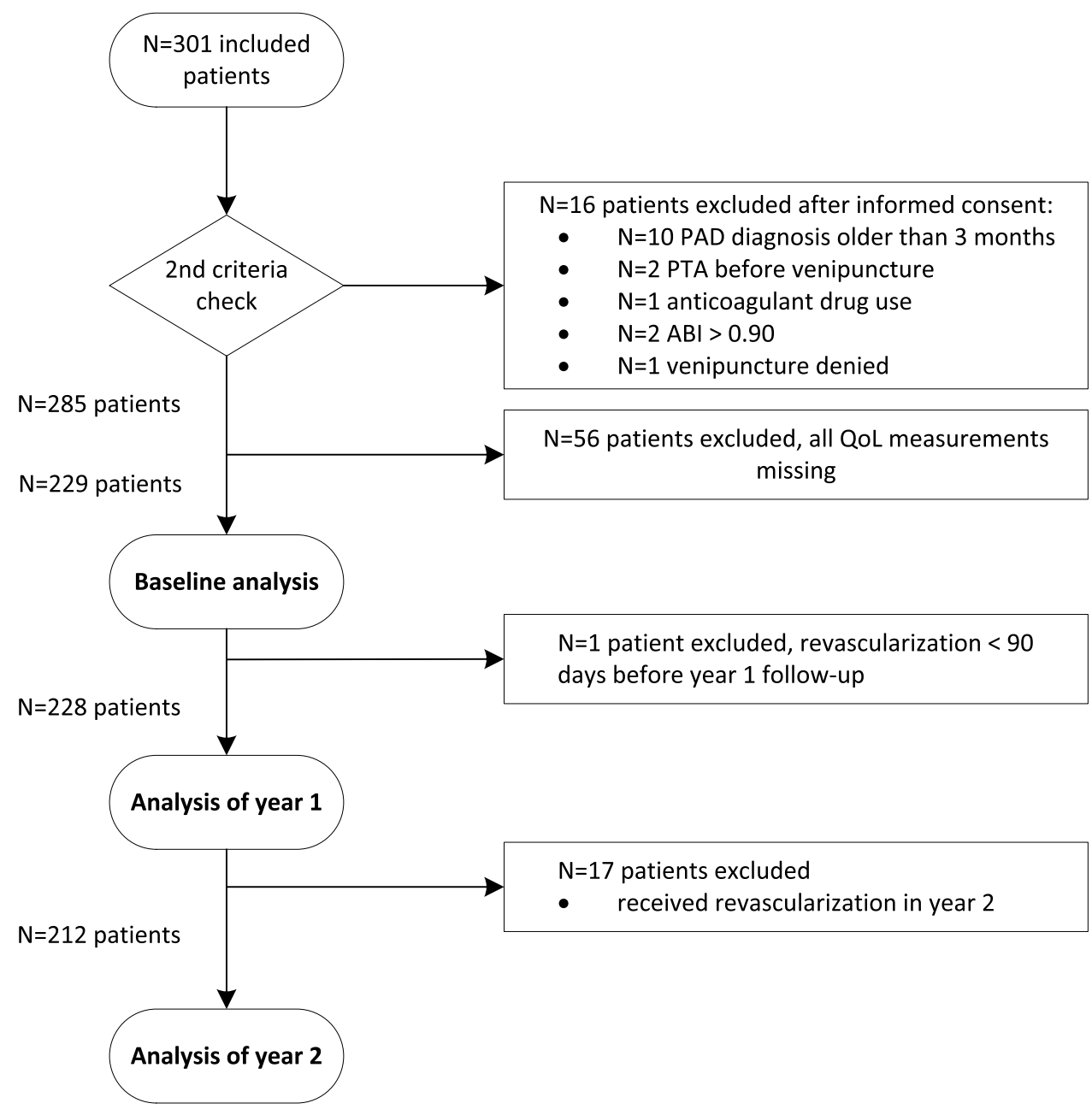


Table 2 Baseline characteristics, frequencies and missingness

\begin{tabular}{|c|c|c|}
\hline Characteristic & $\mathrm{N}^{\mathrm{a}}(\%)$ & Missing values (\%) \\
\hline \multicolumn{3}{|l|}{ Demographics } \\
\hline Male gender & $148(64.6)$ & $0(0)$ \\
\hline Currently smoking & $122(53.3)$ & $1(1)$ \\
\hline Age $\pm S D$ & $65.8 \pm 8.1$ & $0(0)$ \\
\hline Body mass index $\pm \mathrm{SD}$ & $26.6 \pm 4.1$ & $31(13)$ \\
\hline \multicolumn{3}{|l|}{ Disease severity } \\
\hline Fontaine I & $9(3.9)$ & $1(1)$ \\
\hline Fontaine IIa & $136(59.4)$ & \\
\hline Fontaine IIb & 77 (33.6) & \\
\hline Fontaine III & $5(2.2)$ & \\
\hline Fontaine IV & $2(0.9)$ & \\
\hline Progressive symptoms & $116(50.7)$ & $0(0)$ \\
\hline Rest pain & $40(17.5)$ & $2(1)$ \\
\hline Complaints in daily life & $128(55.9)$ & $5(2)$ \\
\hline Claudication distance $<100 \mathrm{~m}$ & $61(26.6)$ & $4(2)$ \\
\hline Ankle-brachial-index $\pm \mathrm{SD}$ & $0.72 \pm 0.19$ & $0(0)$ \\
\hline \multicolumn{3}{|l|}{ Comorbidities } \\
\hline Stroke & $29(12.7)$ & $0(0)$ \\
\hline Myocardial infarction & $28(12.2)$ & $0(0)$ \\
\hline No diabetes & $190(83.0)$ & $0(0)$ \\
\hline Untreated diabetes & $5(2.2)$ & \\
\hline Diabetes mellitus II & $27(11.8)$ & \\
\hline Diabetes mellitus I & $7(3.1)$ & \\
\hline Hypertension & $121(54.1)$ & $0(0)$ \\
\hline Cholesterol-lowering drug use & $188(82.1)$ & $0(0)$ \\
\hline Elevated D-Dimer & $72(31.4)$ & $6(3)$ \\
\hline Impaired kidney function & $48(21.0)$ & $30(13)$ \\
\hline Malignancies & $21(9.2)$ & $0(0)$ \\
\hline
\end{tabular}

$S D$ standard deviation

${ }^{\text {a }}$ Patient characteristics after imputation of missing values

Post hoc analyses of the ANCOVA models (Table 4) produced PS-matched EMMs of revascularisation and conservative treatment at year 1. EMMs after revascularisation are consistently positive, while those of conservative treatment are positive and negative (see Fig. 2b in Appendix 1). EMMs of revascularisation and conservative treatment do not differ significantly. Between the metrics, EMMs and mean differences vary in magnitude, EQ-5D EMMs and SF-6D mean differences are largest, VAS EMMs are lowest and the mean difference is negative. Scenario analyses confirm these observations, only the complete case scenario produced scores somewhat different (see Appendix 4).

\section{Sustainability of and heterogeneity in revascularisation effect during the second year}

As seen at 1-year follow-up, patients revascularised in year one reported less problems with pain/discomfort, mobility and usual activities in the EQ-5D (see Fig. 3 in Appendix 1). All SF-6D domain scores were increased compared to baseline and year one follow-up except for physical function, which decreased compared to year one follow-up but remained increased compared to baseline (see Fig. 4 in Appendix 1).

Baseline QoL and rest pain are significant covariates of QoL change after treatment, while all other baseline patient characteristics and treatment group were not significant covariates (Table 3). QoL gains after treatment are larger in patients with low baseline QoL, and lower in patients with rest pain.

As at year 1, year 2 EMMs after revascularisation are consistently positive and those of conservative treatment are positive and negative (see Fig. 2c in Appendix 1). Unlike in year 1, all mean differences are positive, yet not statistically significant (Table 4). In comparison to year 1, EMMs of revascularisation were increased, stagnated and decreased measured by SF-6D, EQ-5D and VAS, respectively. Between the metrics, EMMs and mean differences vary in magnitude, the EQ-5D has the largest scores. Scenario analyses also confirm these observations and show similar scores, only the complete case scenario produced scores somewhat different (see Appendix 4).

\section{Discussion}

\section{Main findings}

A year after diagnosis, the effect of revascularisation on QoL is insignificantly positive, and is influenced by baseline QoL. The effect of revascularisation is insignificantly larger than the effect of conservative treatment. Two years after diagnosis, the positive effect of revascularisation on QoL is sustained. Factors influencing the maintained effect of revascularisation on QoL are baseline QoL and rest pain, the latter only on EQ-5D scores. Compared to the first year, a decreased, stable and increased revascularisation effect is depicted by SF-6D, EQ-5D and VAS, respectively. Magnitude of revascularisation effect is generally largest when considering the EQ-5D.

\section{Interpretation}

We found positive effects of revascularisation on $\mathrm{QoL}$ at years 1 and 2 measurements. This is in line with literature reporting QoL gains of 0.07 to 0.19 measured with the EQ-5D [10,37, 38], significant increases in all SF-36 domains [11] and a VAS gain of 0.121 year after revascularisation [38]. Moreover, EQ-5D, VAS and SF-36 domain scores 2 years after PAD diagnosis were in line with long-term follow-up scores measured 11 years after revascularisation in van Hattum et al. [39]. Regression analysis had previously shown age, BMI, education, severity of disease and baseline general health to predict SF-36 domain scores 1 year after revascularisation $[11,40]$. A different study had found age and diabetes to correlate with SF-36 scores between 1 and 7 years after 
Table 3 ANCOVA analysis: coefficients of QoL change baseline - year 1 , and baselineyear 2

\begin{tabular}{|c|c|c|c|c|c|c|c|c|c|}
\hline \multirow[t]{2}{*}{ Model coefficients } & \multicolumn{3}{|l|}{ SF-6D } & \multicolumn{3}{|l|}{ EQ-5D } & \multicolumn{3}{|l|}{ VAS } \\
\hline & B & SE & Sig. & B & SE & Sig. & B & SE & Sig. \\
\hline \multicolumn{10}{|l|}{ Year 1} \\
\hline (Intercept) & 0.427 & 0.108 & 0.001 & 0.529 & 0.074 & 0.000 & 0.543 & 0.119 & 0.000 \\
\hline Conservative treatment & -0.055 & 0.042 & 0.205 & -0.038 & 0.057 & 0.506 & 0.002 & 0.072 & 0.978 \\
\hline Baseline SF-6D & -0.587 & 0.163 & 0.001 & - & - & - & - & - & - \\
\hline Baseline EQ-5D & - & - & - & -0.774 & 0.119 & 0.000 & - & - & - \\
\hline Baseline VAS & - & - & - & - & - & - & -0.817 & 0.211 & 0.002 \\
\hline \multicolumn{10}{|l|}{ Year 2} \\
\hline (Intercept) & 0.394 & 0.139 & 0.008 & 0.637 & 0.077 & 0.000 & 0.481 & 0.157 & 0.007 \\
\hline Conservative treatment & -0.035 & 0.038 & 0.360 & -0.064 & 0.077 & 0.416 & -0.031 & 0.063 & 0.630 \\
\hline Rest pain & -0.030 & 0.047 & 0.516 & -0.167 & 0.073 & 0.026 & 0.000 & 0.095 & 0.996 \\
\hline Baseline SF-6D & -0.564 & 0.200 & 0.008 & - & - & - & - & - & - \\
\hline Baseline EQ-5D & - & - & - & -0.870 & 0.117 & 0.000 & - & - & - \\
\hline Baseline VAS & - & - & - & - & - & - & -0.713 & 0.219 & 0.005 \\
\hline
\end{tabular}

This analysis is based on propensity score-matched data

$B$ beta-coefficient, Sig. significance, $S E$ standard error

\begin{tabular}{clrrrrr}
\hline & \multicolumn{2}{l}{ Estimated marginal means (SE) } & \multirow{2}{l}{$P$ value } & $R^{2 \mathrm{a}}$ & \multirow{2}{*}{ Adjusted $R^{2 \mathrm{a}}$} \\
\cline { 2 - 4 } & \multicolumn{1}{l}{ Rev } & \multicolumn{1}{l}{ Cons } & & & \\
\hline Year 1 & & & & & \\
SF-6D & $0.038(0.021)$ & $-0.017(0.042)$ & $0.055(0.042)$ & 0.205 & $0.141-0.382$ & $0.128-0.373$ \\
EQ-5D & $0.077(0.041)$ & $0.038(0.040)$ & $0.038(0.057)$ & 0.506 & $0.308-0.551$ & $0.398-0.545$ \\
VAS & $0.019(0.053)$ & $0.021(0.048)$ & $-0.002(0.072)$ & 0.978 & $0.227-0.461$ & $0.216-0.453$ \\
Year 2 & & & & & & \\
SF-6D & $0.015(0.025)$ & $-0.020(0.032)$ & $0.035(0.038)$ & 0.360 & $0.050-0.251$ & $0.026-0.231$ \\
EQ-5D & $0.077(0.043)$ & $0.013(0.060)$ & $0.064(0.077)$ & 0.416 & $0.354-0.499$ & $0.338-0.487$ \\
VAS & $0.027(0.036)$ & $-0.004(0.055)$ & $0.031(0.063)$ & 0.630 & $0.059-0.420$ & $0.035-0.405$ \\
\hline
\end{tabular}

$R e v$ revascularised, Con conservative treatment, $S E$ standard error

${ }^{a} R^{2}$ are presented as ranges due to the presence of multiple imputation datasets
Table 4 ANCOVA post hoc analysis: estimated marginal means of treatment at year 1 and year 2 revascularisation or amputation for PAD; rest pain was tested and found to be insignificant, QoL before the intervention was not tested as a predictor [40]. Differences in patient characteristics, outcome measures and variables in the regression analyses hamper the comparison of these results.

As a result of adaptation and coping, patient VAS scores, as estimates of a patient's own QoL, tend to be higher than EQ-5D scores which reflect the public's preferences for a patient's health state description [12, 41, 42]. Our results are in line with these expectations. Furthermore, the mean difference between baseline EQ-5D and SF-6D in our study (EQ-5D 0.052 points larger than SF-6D) was similar to that in other patient populations [43]. The observation that the effect of revascularisation on QoL was larger measured by the EQ-5D might be explained by a floor effect of the SF-6D. The SF-6D, as it was designed to assess QoL in the general population, tends to produce relatively high utility values in patients with a larger disease burden [5, 39]. Figure 5 in Appendix 1 shows that in our sample, values below 0.55 were rare. This floor effect can then cause decreased sensitivity in health states of lower QoL [5, 14, 27, 43-45]. Consistently, it has been hypothesised that QoL valued by the patients themselves have a ceiling effect and reduced discriminative capabilities, which might explain low VAS change scores [12]. Figure 5 in Appendix 1 indicates scores above 0.9 were rare. However, previous studies also identified a potential weakness of the EQ-5D, the overestimation of QoL due to the avoidance of the third and most severe level [29, 43]. In other populations, less than $1 \%$ made use of level 3 of the domain 'mobility'. Avoidance of mobility level 3 can cause an insensitivity of the EQ-5D to improvements in mobility. Figure 3 shows that in our study, only $0-3 \%$ of patients responded with level 3 in this domain. Insensitivity to change, however, was not indicated in our results considering mobility was a significant driver of QoL change after treatment. Moreover, a previous literature review concluded the EQ-5D to be more sensitive to change than other generic measures in PAD patients [19], results that we confirmed with the comparatively large estimated marginal means of treatment and the comparatively large difference between treatment groups. 


\section{Strengths and weaknesses}

A first strength of this study is the selection of participants; the study population consisting of patients referred to the vascular surgery department for PAD diagnosis reflects the spectrum of PAD patients, including patients with varying medical history and PAD severity. Our outcomes are likely generalisable to PAD patients in secondary care overall. Secondly, by using PS matching, the observational data were resampled to allow for comparisons of revascularised and conservatively treated patients, thereby enabling comparisons of treatment effect. Thirdly, by analysing three widely used QoL metrics, one of them being the current standard in assessing QoL for economic evaluations in, for instance, the Netherlands [28] and the United Kingdom [46], and comparing their scores and performances, this study provides well-needed insight into the strengths and weaknesses as well as the suitability of the metrics for economic evaluations regarding treatment of PAD.

The study also suffered from several limitations. The inclusion time just short of 5 years may have allowed for techniques to evolve over time so that patients might have been exposed to varying treatment methods. Expert opinion indicated these developments were not substantial at the study site. Patients using coagulation-altering medication were excluded. Given these medications will be prescribed for atrial fibrillation, a condition vastly affecting QoL [47-49], the excluded patients might be a subgroup with especially low QoL. As a result, our QoL estimates may be an overestimation of the QoL in the total incident PAD population. Another weakness is that, although this is extremely unlikely given the patients' long treatment records in the participating hospitals, we cannot rule out that patients could have received revascularisation elsewhere that was not reported. Our research also highlighted several implications for further research. Given the variability of revascularisation effect after accounting for a number of patient characteristics, further research should identify patient characteristics of influence, e.g. socioeconomic determinants such as SES, housing and activity level in daily life, or further PAD-specific determinants such as length and location of the occlusion. The relatively small sample size, especially of revascularised patients, may be a weakness of the study as it may have caused relationships or differences that are present to be statistically insignificant. In this respect, it is important to recall that absence of evidence is not evidence of absence [50]. And lastly, the umbrella term (peripheral) revascularisation summarises a number of interventions aimed at restoring blood flow to the leg. Considering the on-going discussion about patency of endovascular vs. surgical revascularisation [51], further research should compare the sustainability of QoL gains acquired by different revascularisation techniques. Data from randomised controlled trials would furthermore negate the need for propensity score matching as an adjustment for confounding by indication, and would thereby enable stronger conclusions about the comparison of treatments.

\section{Conclusion}

The findings of this study show that conservative and invasive treatment both have a positive effect on QoL, and the effect of invasive treatment is sustained over 2 years. Significance tests show no difference between the treatment options. The results of our analyses confirmed advantages of the EQ-5D in detecting change over time and differences between groups. Our results therefore indicate that EQ-5D utilities may be most suitable for QoL measurement in patients with PAD, and support the preferential application of the EQ-5D in this population. The finding that the magnitude of revascularisation effect is influenced by baseline QoL may be relevant for clinical decision making, as it can give an a priori estimation of the expected QoL gain in individual patients.

Acknowledgements We want to thank the discussants and attendees of the Lowlands Health Economic Study Group Conference 2018 for an interesting and fruitful discussion of the manuscript. Furthermore, we want to thank all patients, nurses and clinicians involved in the INCOAG study for their significant contributions.

\section{Compliance with ethical standards}

Conflict of interest SP, BR, AC, JD and MJ have nothing to disclose. RO reports personal fees from Daiichi Sankyo, personal fees from Bayer, personal fees from Pfizer/BMS, outside the submitted work. HC reports grants from Bayer, grants from Boehringer Ingelheim, grants from Pfizer/BMS, personal fees from Stago, grants from Leo Pharma, outside the submitted work and $\mathrm{HC}$ is an unpaid chairman of the board of the Dutch Federation of Anticoagulation clinics.

Ethical approval All procedures performed in studies involving human participants were in accordance with the ethical standards of the institutional and/or national research committee and with the 1964 Helsinki Declaration and its later amendments or comparable ethical standards.

Informed consent Informed consent was obtained from all individual participants included in the study.

Open Access This article is distributed under the terms of the Creative Commons Attribution 4.0 International License (http://creativeco mmons.org/licenses/by/4.0/), which permits unrestricted use, distribution, and reproduction in any medium, provided you give appropriate credit to the original author(s) and the source, provide a link to the Creative Commons license, and indicate if changes were made.

\section{Appendix 1: Additional analyses baseline}

See Tables 5, 6 and 7 and Figures 2, 3, 4 and 5. 
Table 5 Available and missing data, scores at floor and ceiling

\begin{tabular}{llll}
\hline & Baseline & 1-Year follow-up & 2-Year follow-up \\
\hline $\mathrm{N}$ & 229 & 225 & 218 \\
At least one QoL score available & $91.3 \%$ & $66.8 \%$ & $69.4 \%$ \\
SF-6D missing & $28.4 \%$ & $41.5 \%$ & $42.4 \%$ \\
EQ-5D missing & $16.6 \%$ & $35.4 \%$ & $33.6 \%$ \\
VAS missing & $17.5 \%$ & $35.8 \%$ & $34.1 \%$ \\
\hline
\end{tabular}

Table 6 Characteristics of patients with and without missing QoL measurements

\begin{tabular}{|c|c|c|c|c|c|c|c|c|c|}
\hline \multirow{2}{*}{$\begin{array}{l}\text { Character- } \\
\text { istic }\end{array}$} & \multicolumn{5}{|l|}{ Baseline } & \multicolumn{2}{|l|}{ Year 1} & \multicolumn{2}{|l|}{ Year 2} \\
\hline & $\begin{array}{l}\text { Complete } \\
\text { cohort (229) }\end{array}$ & Rev. (70) & Cons. (159) & $\begin{array}{l}\text { All instru- } \\
\text { ments } \\
\text { completed } \\
(142)\end{array}$ & $\begin{array}{l}\text { One or more } \\
\text { missing (87) }\end{array}$ & $\begin{array}{l}\text { All instru- } \\
\text { ments } \\
\text { completed } \\
(127)\end{array}$ & $\begin{array}{l}\text { One or more } \\
\text { missing (98) }\end{array}$ & $\begin{array}{l}\text { All instru- } \\
\text { ments } \\
\text { completed } \\
(127)\end{array}$ & $\begin{array}{l}\text { One or more } \\
\text { missing }(91)\end{array}$ \\
\hline $\begin{array}{l}\text { SF-6D } \\
\text { (mean } \\
\quad(\mathrm{SE}))\end{array}$ & 0.689 (0.009) & $0.651(0.015)$ & $0.706(0.010)$ & $0.710(0.011)$ & $0.655(0.015)$ & $\mathbf{0 . 7 4 8}(0.011)$ & $\mathbf{0 . 6 5 4}(0.013)$ & $\mathbf{0 . 7 4 6}(0.012)$ & $\mathbf{0 . 6 5 7}(0.013)$ \\
\hline $\begin{array}{l}\text { EQ-5D } \\
\text { (mean } \\
(\mathrm{SE}))\end{array}$ & $0.637(0.019)$ & $0.571(0.036)$ & $0.666(0.020)$ & $0.664(0.020)$ & $0.594(0.037)$ & $\mathbf{0 . 7 2 9}(0.018)$ & $\mathbf{0 . 6 2 3}(0.028)$ & $0.738(0.019)$ & ) $0.667(0.028)$ \\
\hline $\begin{array}{l}\text { VAS (mean } \\
\quad(\mathrm{SE}) \text { ) }\end{array}$ & $0.665(0.015)$ & $0.629(0.029)$ & $0.681(0.018)$ & $0.684(0.013)$ & $0.633(0.032)$ & $0.711(0.016)$ & $0.654(0.040)$ & $0.712(0.016)$ & $0.675(0.039)$ \\
\hline Age (mean) & 65.8 & 64.0 & 66.5 & 65.3 & 66.5 & 66.0 & 65.7 & 64.9 & 66.8 \\
\hline $\operatorname{Men}(\%)$ & 64.6 & 67.1 & 63.5 & 68.3 & 58.6 & 69.3 & 57.1 & 72.4 & 54.9 \\
\hline ABI (mean) & 0.72 & 0.70 & 0.73 & 0.71 & 0.73 & 0.71 & 0.73 & 0.69 & 0.76 \\
\hline $\begin{array}{l}\text { Current } \\
\text { smoker } \\
(\%)\end{array}$ & 53.3 & 58.6 & 50.9 & 55.6 & 49.4 & 54.3 & 53.1 & 58.3 & 47.1 \\
\hline $\begin{array}{l}\text { Severe Fon- } \\
\text { taine stage } \\
(\%)\end{array}$ & 36.7 & 51.4 & 30.2 & 32.4 & 43.7 & 31.5 & 43.9 & 29.9 & 45.1 \\
\hline $\begin{array}{l}\text { Progressive } \\
\text { symptoms } \\
(\%)\end{array}$ & 50.7 & 74.3 & 40.3 & 51.4 & 49.4 & 48.8 & 52.0 & 48.8 & 52.9 \\
\hline $\begin{array}{l}\text { Hyperten- } \\
\text { sion }(\%)\end{array}$ & 54.1 & 51.4 & 53.5 & 53.5 & 51.7 & 52.0 & 57.1 & 50.4 & 55.9 \\
\hline $\begin{array}{l}\text { Hypercho- } \\
\text { lester- } \\
\text { olemia (\%) }\end{array}$ & 49.8 & 45.7 & 51.6 & 46.5 & 55.2 & 52.0 & 48.0 & 52.0 & 47.1 \\
\hline Diabetes (\%) & 17.0 & 15.7 & 17.6 & 16.9 & 17.2 & 16.5 & 15.3 & 15.7 & 18.6 \\
\hline $\begin{array}{l}\text { Myocardial } \\
\text { infarction } \\
(\%)\end{array}$ & 12.2 & 7.1 & 14.5 & 11.3 & 13.8 & 8.6 & 16.3 & 10.2 & 14.7 \\
\hline Stroke $(\%)$ & 12.7 & 17.1 & 10.7 & 12.7 & 12.6 & 12.6 & 11.2 & 12.7 & 11.8 \\
\hline
\end{tabular}

Significantly different utilities marked bold

Rev revascularisation procedure, including endovascular interventions, e.g. angioplasty with and without stent placement, and open surgery, e.g. atherectomy and endarterectomy, and bypass surgery, Cons conservative treatment, $S E$ standard error 
Table 7 Baseline heterogeneity in quality of life

\begin{tabular}{|c|c|c|c|c|c|c|c|c|c|}
\hline \multirow[t]{2}{*}{ Characteristic } & \multicolumn{3}{|l|}{ SF-6D } & \multicolumn{3}{|c|}{ EQ-5D } & \multicolumn{3}{|l|}{ VAS } \\
\hline & Mean & $(\mathrm{SE})$ & Median $^{\mathrm{a}}$ & Mean & $(\mathrm{SE})$ & Median $^{\mathrm{a}}$ & Mean & $(\mathrm{SE})$ & Median $^{\mathrm{a}}$ \\
\hline \multicolumn{10}{|l|}{ Demographics } \\
\hline Male gender & 0.692 & 0.011 & 0.696 & 0.632 & 0.022 & 0.691 & 0.663 & 0.022 & 0.700 \\
\hline Female gender & 0.684 & 0.014 & 0.673 & 0.647 & 0.030 & 0.691 & 0.668 & 0.024 & 0.700 \\
\hline Currently smoking & 0.671 & 0.012 & 0.666 & 0.619 & 0.024 & 0.691 & 0.650 & 0.022 & 0.700 \\
\hline Currently not smoking & 0.710 & 0.013 & 0.704 & 0.658 & 0.027 & 0.726 & 0.682 & 0.026 & 0.700 \\
\hline Age $>75$ & 0.672 & 0.024 & 0.683 & 0.633 & 0.053 & 0.691 & 0.651 & 0.048 & 0.700 \\
\hline Age $<75$ & 0.692 & 0.010 & 0.696 & 0.638 & 0.020 & 0.691 & 0.667 & 0.019 & 0.700 \\
\hline Body mass index $>30$ & 0.657 & 0.018 & 0.642 & 0.596 & 0.047 & 0.691 & 0.626 & 0.037 & 0.640 \\
\hline Body mass index $<30$ & 0.696 & 0.010 & 0.696 & 0.647 & 0.019 & 0.691 & 0.674 & 0.016 & 0.700 \\
\hline \multicolumn{10}{|l|}{ Disease severity } \\
\hline Fontaine mild & 0.704 & 0.011 & 0.700 & 0.670 & 0.020 & 0.691 & 0.679 & 0.019 & 0.700 \\
\hline Fontaine severe & 0.664 & 0.015 & 0.645 & 0.581 & 0.033 & 0.691 & 0.641 & 0.027 & 0.700 \\
\hline Progressive symptoms & 0.662 & 0.013 & 0.649 & 0.587 & 0.026 & 0.691 & 0.639 & 0.020 & 0.700 \\
\hline Non-progressive symptoms & 0.717 & 0.012 & 0.728 & 0.689 & 0.023 & 0.691 & 0.692 & 0.021 & 0.700 \\
\hline Rest pain & 0.626 & 0.017 & 0.614 & 0.558 & 0.039 & 0.620 & 0.587 & 0.035 & 0.600 \\
\hline No Rest pain & 0.703 & 0.010 & 0.699 & 0.654 & 0.022 & 0.691 & 0.681 & 0.016 & 0.700 \\
\hline Complaints in daily life & 0.646 & 0.011 & 0.630 & 0.578 & 0.025 & 0.691 & 0.626 & 0.020 & 0.650 \\
\hline No complaints in daily life & 0.744 & 0.012 & 0.753 & 0.713 & 0.022 & 0.727 & 0.715 & 0.024 & 0.750 \\
\hline Claudication $<100 \mathrm{~m}$ walking & 0.664 & 0.018 & 0.646 & 0.548 & 0.037 & 0.691 & 0.608 & 0.031 & 0.640 \\
\hline Claudication $>100 \mathrm{~m}$ walking & 0.698 & 0.010 & 0.696 & 0.670 & 0.021 & 0.691 & 0.686 & 0.018 & 0.700 \\
\hline Ankle-brachial-index $<0.5$ & 0.703 & 0.028 & 0.753 & 0.622 & 0.056 & 0.691 & 0.688 & 0.049 & 0.700 \\
\hline Ankle-brachial-index $>0.9$ & 0.688 & 0.010 & 0.675 & 0.639 & 0.019 & 0.691 & 0.662 & 0.016 & 0.700 \\
\hline \multicolumn{10}{|l|}{ Comorbidities } \\
\hline Stroke & 0.661 & 0.024 & 0.648 & 0.557 & 0.053 & 0.691 & 0.622 & 0.046 & 0.600 \\
\hline No stroke & 0.693 & 0.010 & 0.677 & 0.649 & 0.020 & 0.691 & 0.671 & 0.015 & 0.700 \\
\hline Myocardial infarction & 0.701 & 0.023 & 0.698 & 0.661 & 0.049 & 0.691 & 0.677 & 0.061 & 0.700 \\
\hline No myocardial infarction & 0.688 & 0.010 & 0.675 & 0.634 & 0.020 & 0.691 & 0.663 & 0.015 & 0.700 \\
\hline Diabetes & 0.674 & 0.020 & 0.669 & 0.631 & 0.044 & 0.691 & 0.628 & 0.037 & 0.675 \\
\hline No diabetes & 0.692 & 0.010 & 0.677 & 0.639 & 0.021 & 0.691 & 0.673 & 0.016 & 0.700 \\
\hline Hypertension & 0.688 & 0.012 & 0.640 & 0.640 & 0.022 & 0.691 & 0.656 & 0.021 & 0.700 \\
\hline No hypertension & 0.691 & 0.013 & 0.635 & 0.635 & 0.029 & 0.691 & 0.674 & 0.022 & 0.700 \\
\hline Cholesterol-lowering drug use & 0.693 & 0.010 & 0.691 & 0.635 & 0.022 & 0.691 & 0.664 & 0.017 & 0.700 \\
\hline No Cholesterol-lowering drug use & 0.671 & 0.020 & 0.637 & 0.649 & 0.032 & 0.691 & 0.669 & 0.034 & 0.700 \\
\hline Elevated D-Dimer ${ }^{b}$ & 0.670 & 0.015 & 0.671 & 0.615 & 0.030 & 0.691 & 0.649 & 0.028 & 0.700 \\
\hline Normal D-Dimer & 0.698 & 0.011 & 0.694 & 0.648 & 0.023 & 0.691 & 0.672 & 0.018 & 0.700 \\
\hline Impaired kidney function $^{c}$ & 0.705 & 0.017 & 0.698 & 0.699 & 0.030 & 0.727 & 0.679 & 0.039 & 0.720 \\
\hline Normal kidney function & 0.685 & 0.010 & 0.673 & 0.621 & 0.022 & 0.691 & 0.661 & 0.017 & 0.700 \\
\hline Malignancies & 0.730 & 0.025 & 0.753 & 0.699 & 0.052 & 0.727 & 0.665 & 0.068 & 0.700 \\
\hline No malignancies & 0.685 & 0.009 & 0.675 & 0.631 & 0.019 & 0.691 & 0.665 & 0.016 & 0.700 \\
\hline
\end{tabular}

$S E$ standard error

${ }^{a}$ Median of all 10 imputed datasets combined

${ }^{\mathrm{b}}$ Elevated D-Dimer is defined as D-Dimer $>500$ when age $<50$, as D-Dimer $>$ age $* 10$ when age $>50$

${ }^{\mathrm{c}}$ Impaired kidney function is defined as MDRD eGFR below 60 
Matched baseline QoL

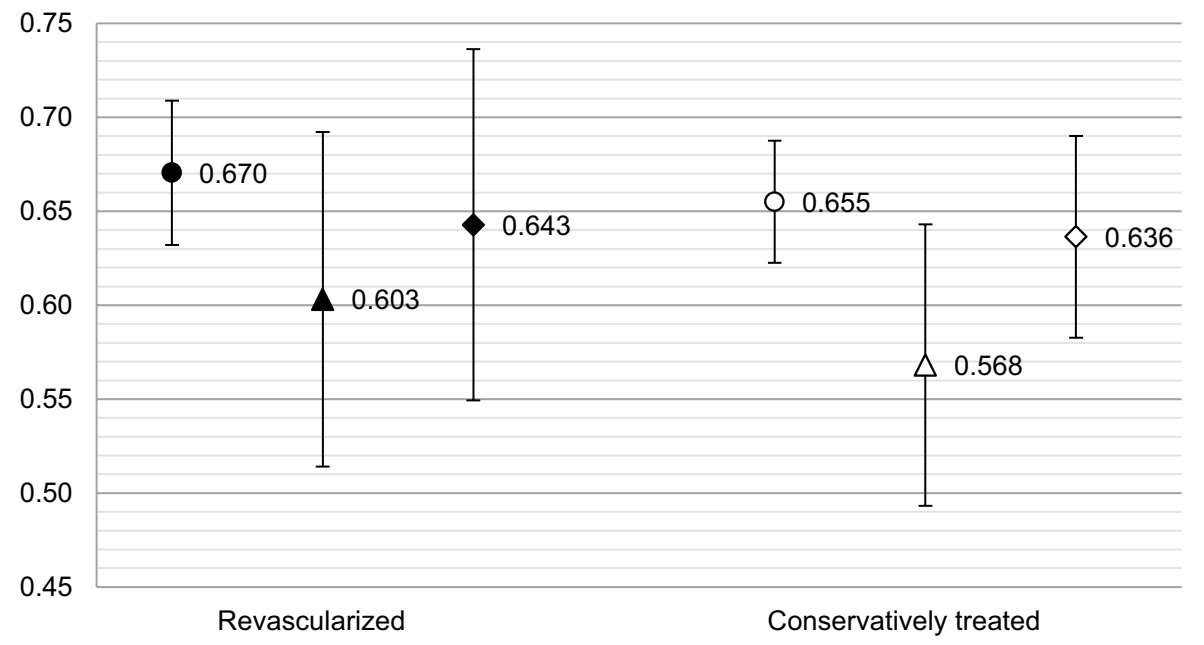

- SF6D

$\triangle \mathrm{EQ5D}$

$\bullet$ VAS

ANCOVA analysis: Estimated marginal means at year 1

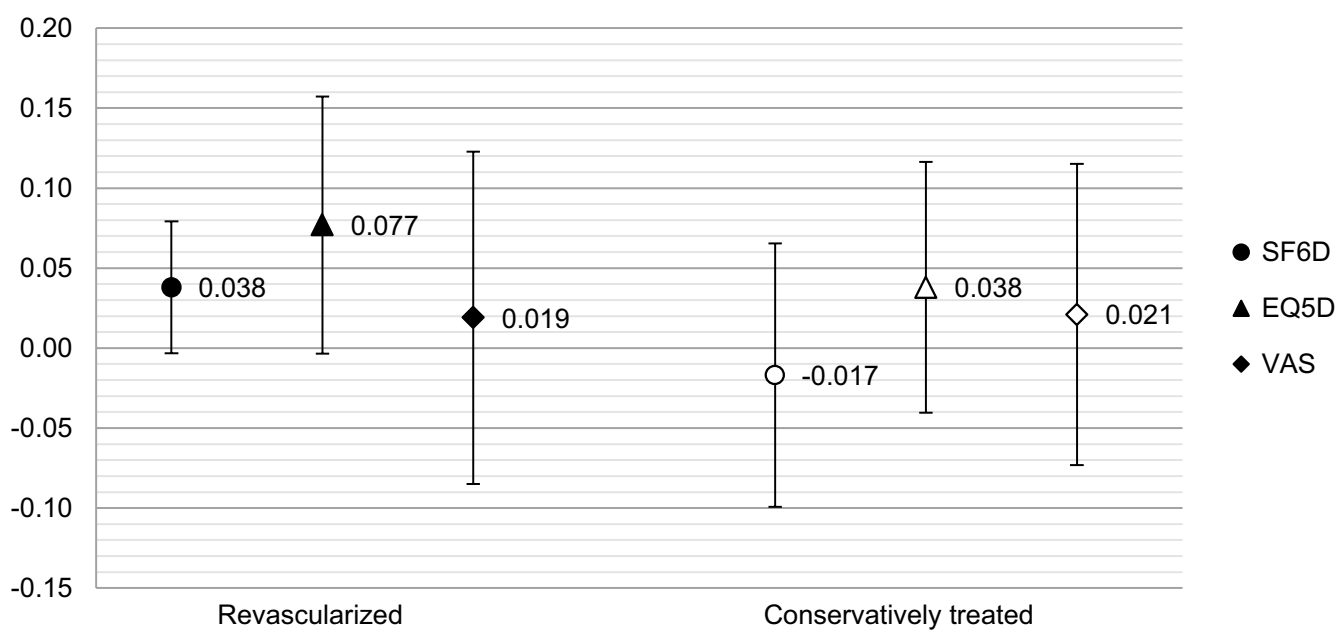

ANCOVA analysis: Estimated marginal means at year 2

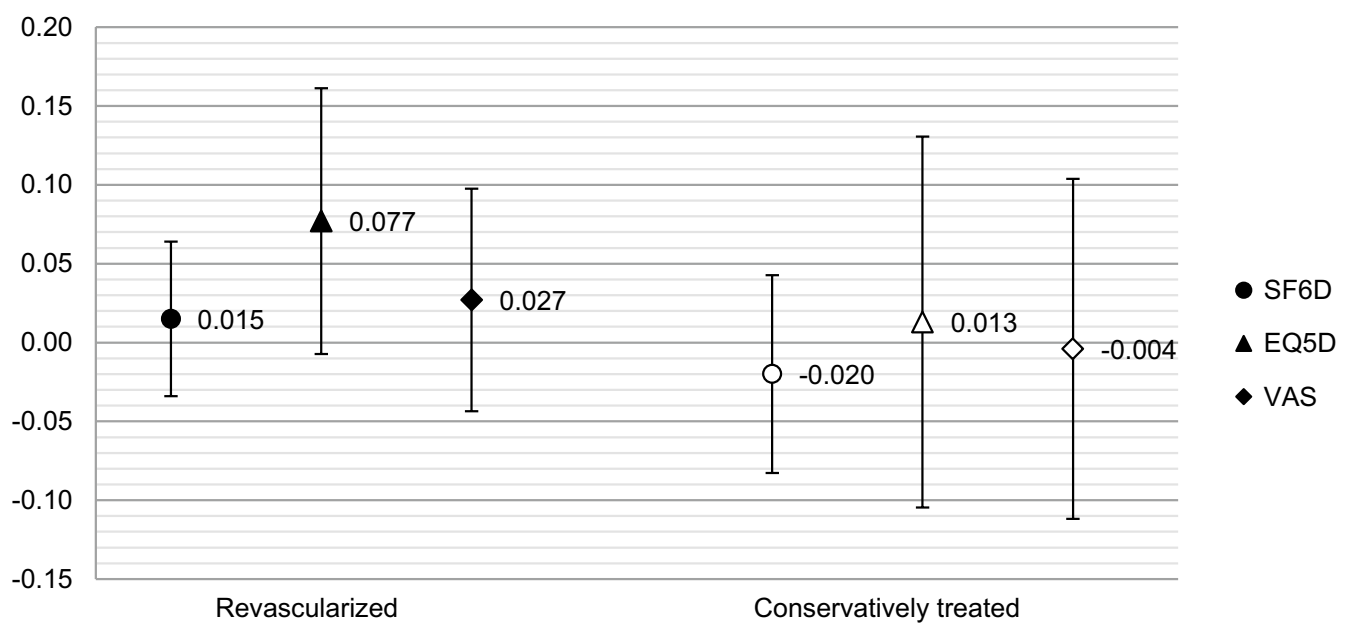

Fig. 2 a-c Matched baseline scores, EMMs of year 1 and EMMs of year 2 
Fig. 3 EQ-5D domains over time
Baseline

Mobility:
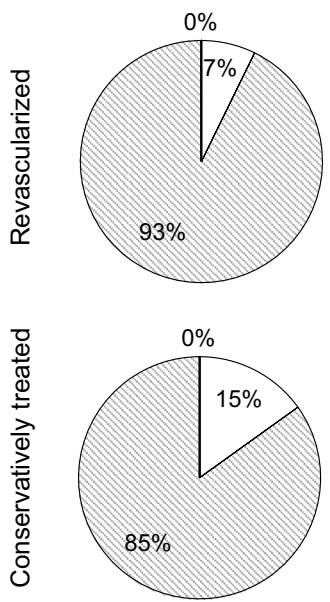

Baseline

Self-care:
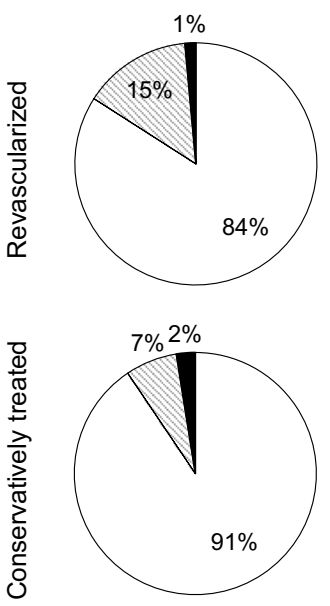

Baseline

Usual activities:
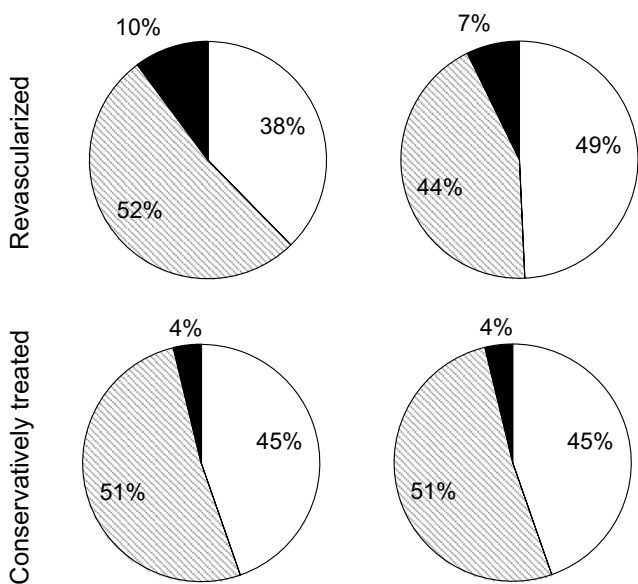

Year 1

Year2
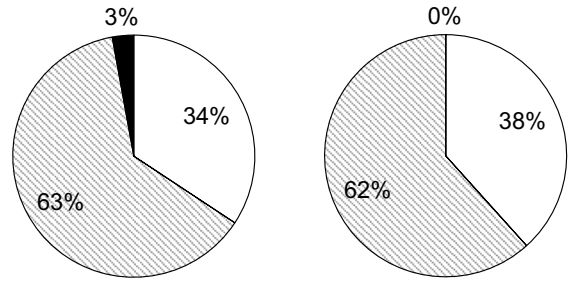

$\square$ No problems

$\checkmark$ Some problems

- Severe problems
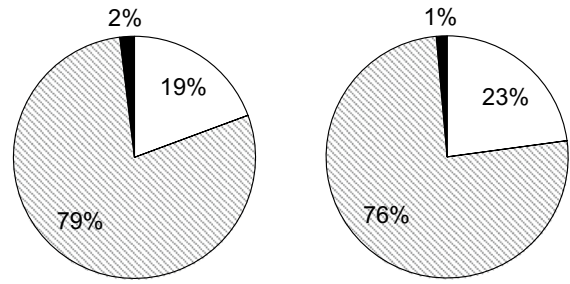

$\square$ No problems

$\checkmark$ Some problems

- Severe problems

$\square$ No problems

$\checkmark$ Some problems

- Severe problems

口No problems

QSome problems

- Severe problems

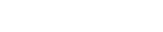

Year2

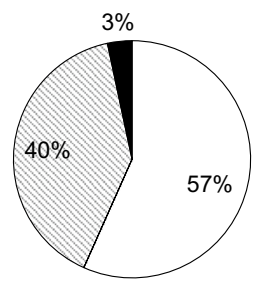

$\square$ No problems

$\square$ Some problems

- Severe problems

$\square$ No problems

$\square$ Some problems

- Severe problems 
Fig. 3 (continued)

Baseline

Pain:
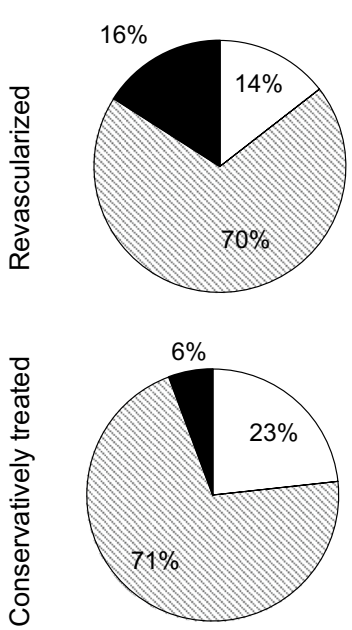

Baseline

Anxiety:
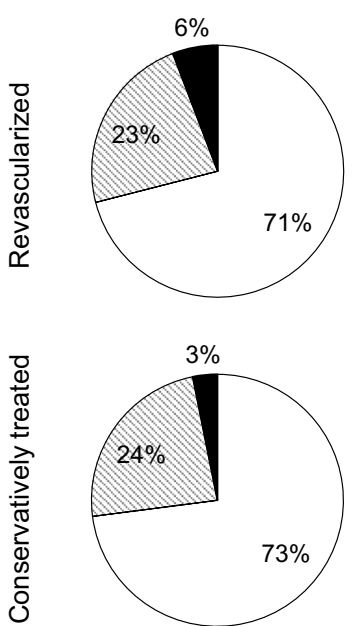

Year 1

Year2
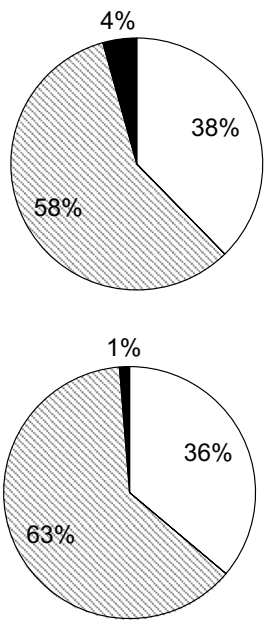

Year 1
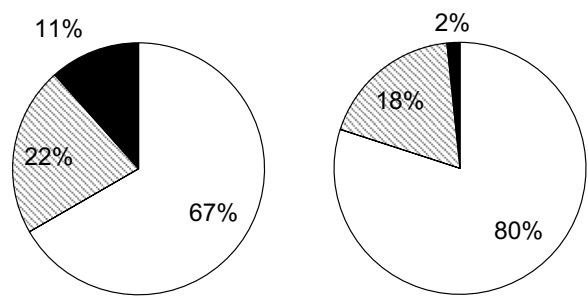

$\square$ No problems

$\checkmark$ Some problems

- Severe problems

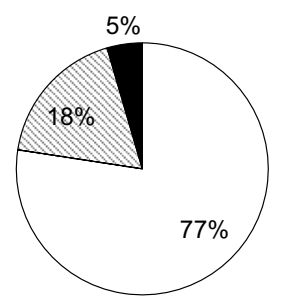

Some problems

- Severe problems

$\square$ No problems

QSome problems

- Severe problems $\square$ No problems
No problems

Some problems

- Severe problems 
Fig. 4 a-h SF-36 domain scores over time* Rev Revascularized, Cons Conservative treatment

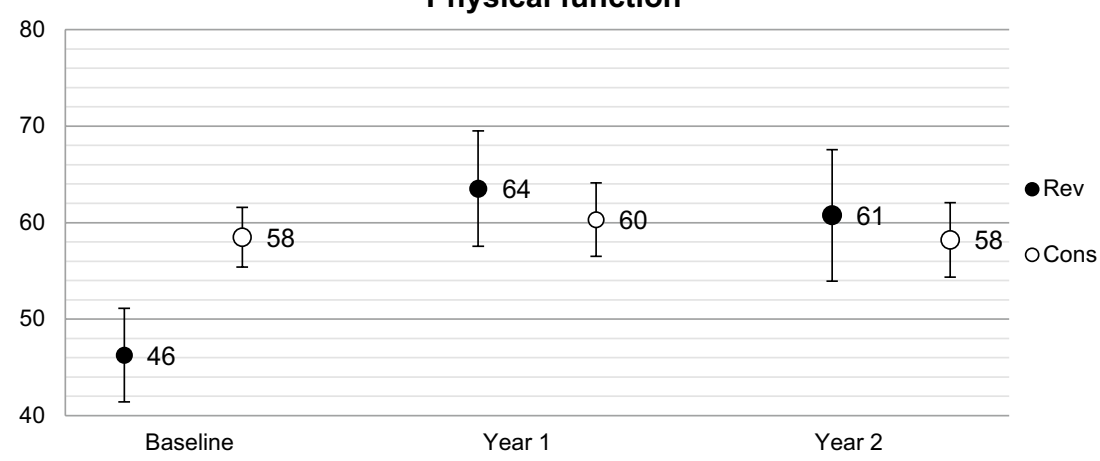

Role limitations physical

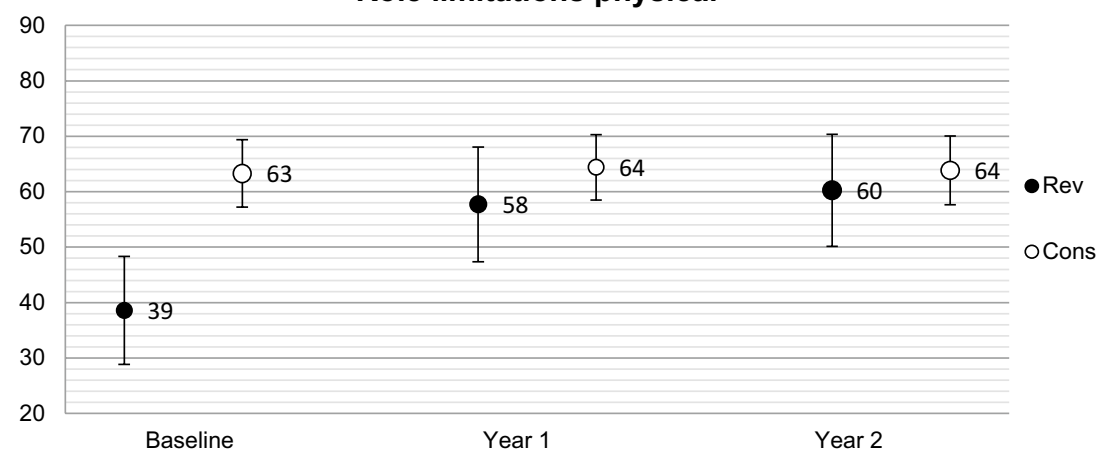

Role limitations emotional

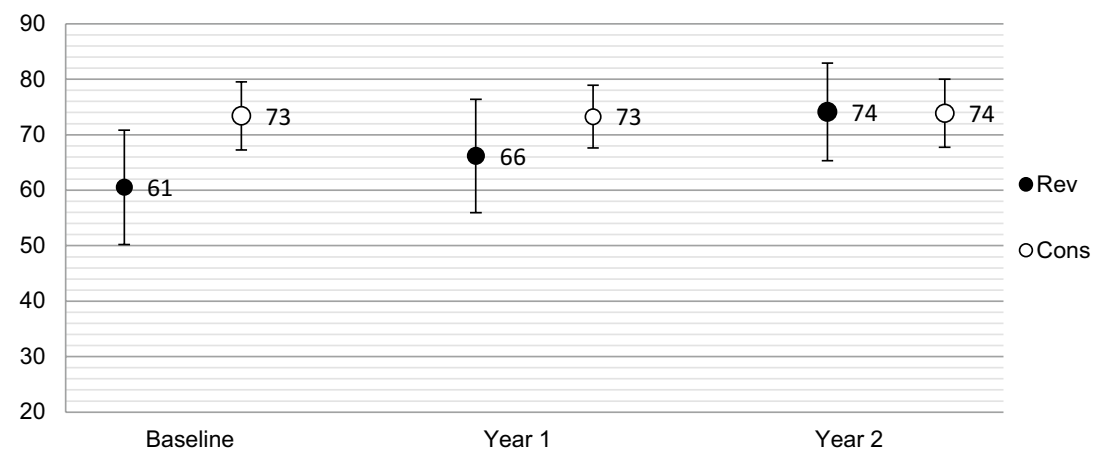

Engergy/Fatigue

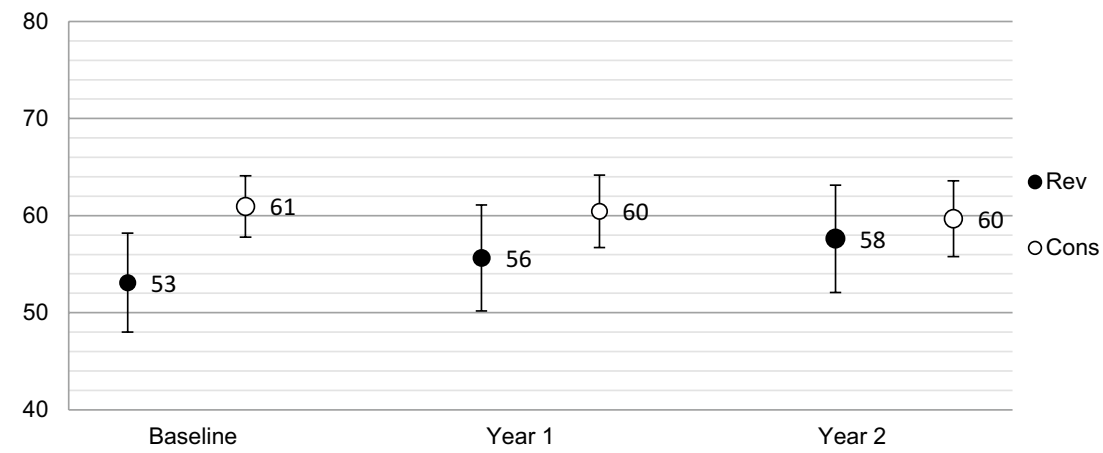


Fig. 4 (continued)

Emotional wellbeing

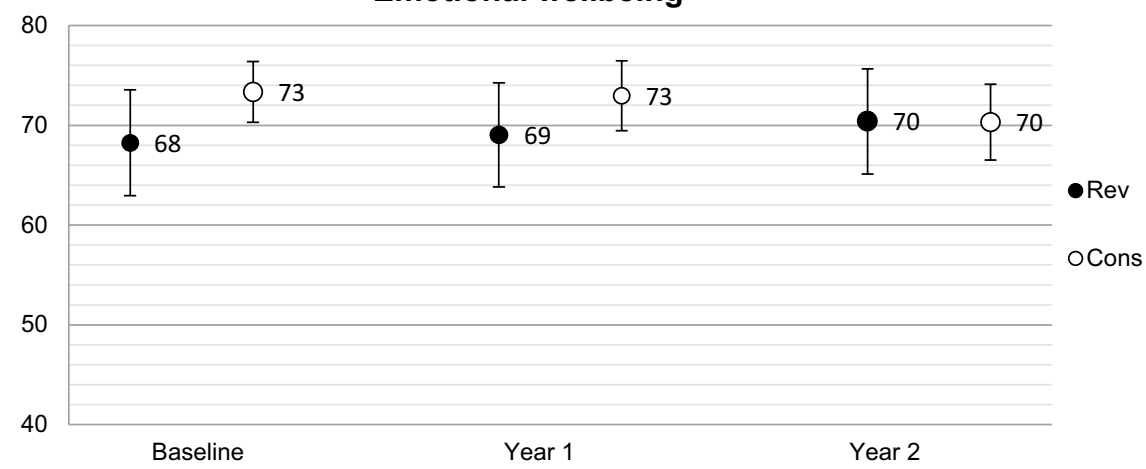

Social functioning
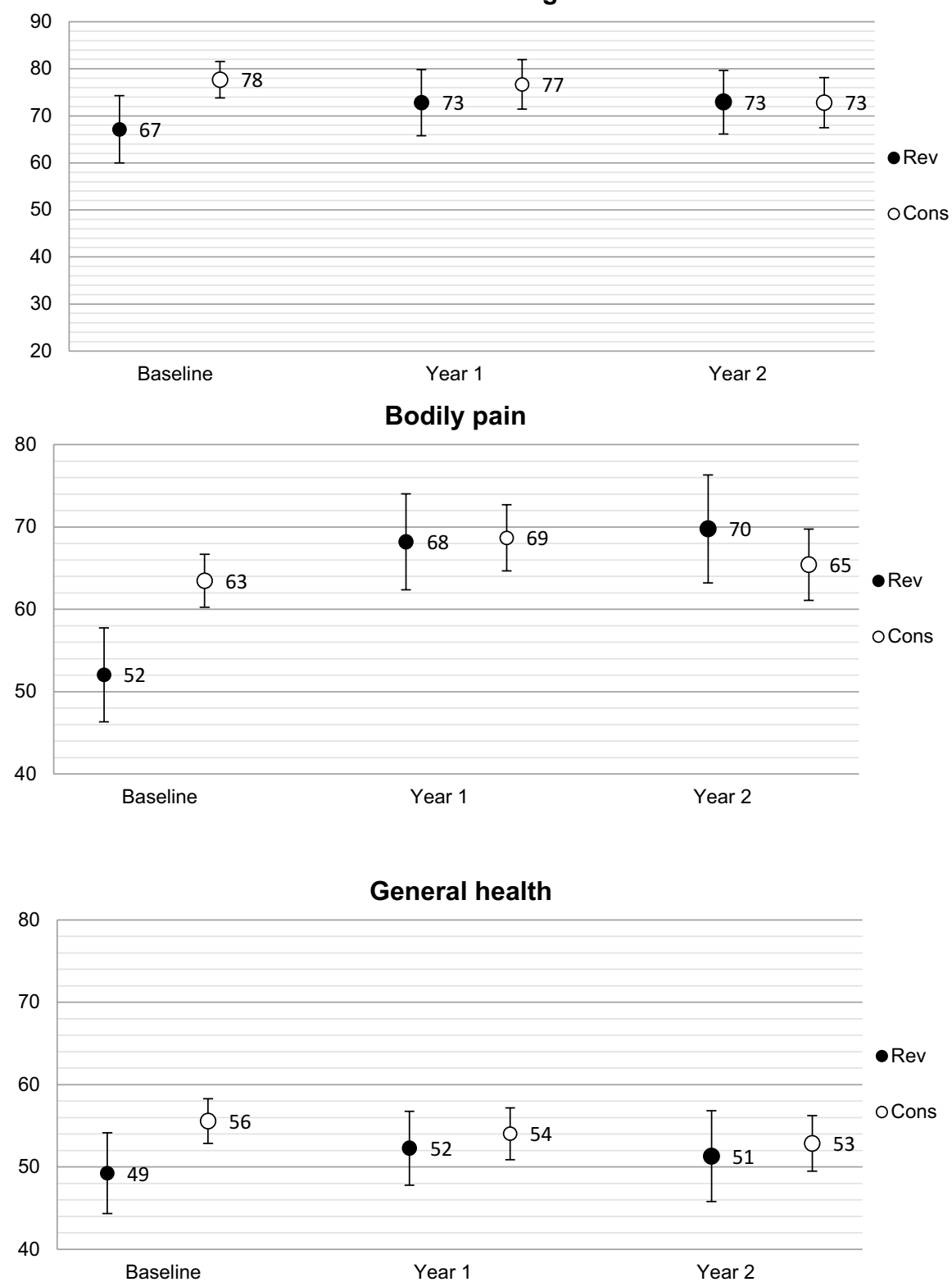
Fig. 5 Floor and ceiling effects

Histogram EQ-5D

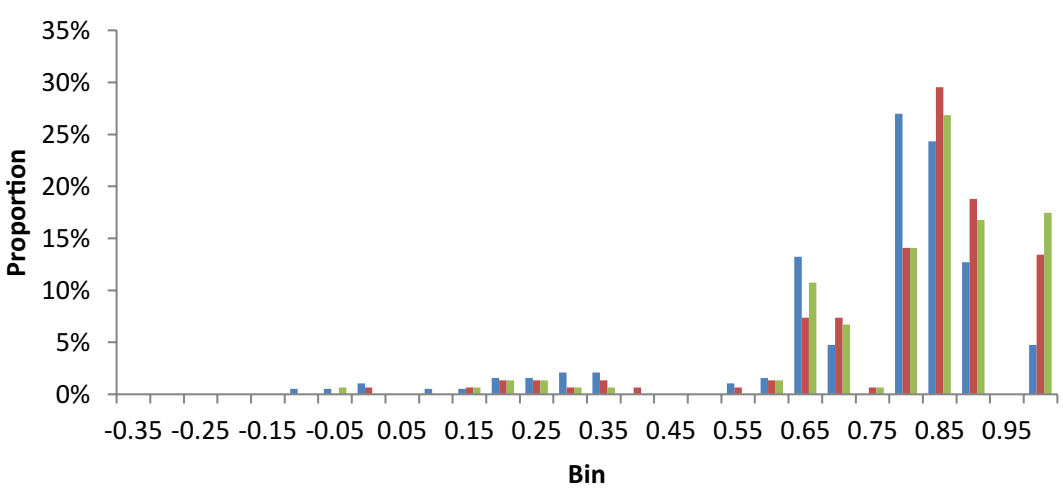

EQ-5D 0

- EQ-5D 12

EQ-5D 24

Histogram SF-6D

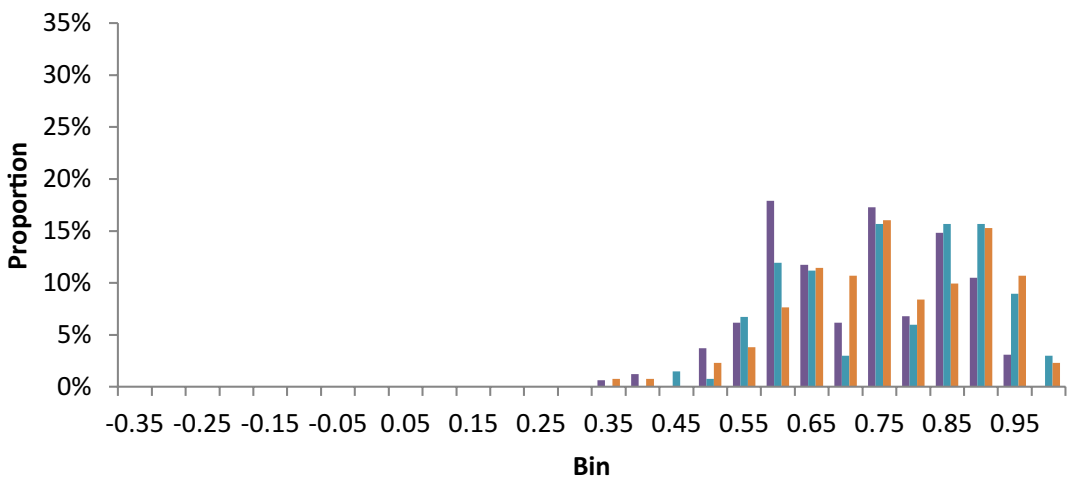

- SF-6D 0

SF-6D 12

SF-6D 24

Histogram VAS

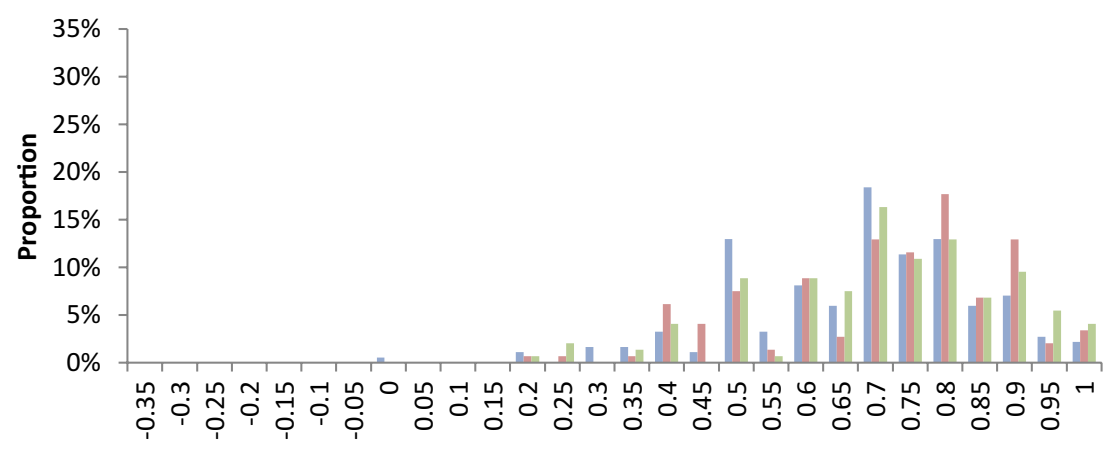

- VAS 0

- VAS 12

VAS 24

Bin 


\section{Appendix 2: Additional information}

List of exclusion criteria:

- PAD diagnosis more than 3 months prior to study inclusion,

- cardiovascular or arterial interventions within the past 6 months,

- (unstable) angina pectoris, myocardial infarction, stroke or heart failure within the past 3 months,

- known coagulation disorders,

- anticoagulant medication use (e.g. Vitamin K antagonists, direct factor Xa-inhibitors and factor II-inhibitors, heparin),

- chronic inflammatory diseases,

- active malignancies,

- repeatedly failed venipunctures,

- being underage,

- not meeting the inclusion criteria.

List of events summarised in the term cardiovascular events:

- transient ischemic attack,

- stroke,

- other cerebral events,

- angina pectoris,

- myocardial infarction,

- other ischemic events,

- coronary revascularisation,

- abdominal aortic aneurysm,

- other artery diseases.

\section{Appendix 3: Propensity score matching}

See Table 8.

List of parameters included in the propensity score:

- Progressive symptoms;

- Complaints in daily life;

- Claudication distance;

- Baseline SF-6D;

- Domains of the SF-36:

- Physical Function;

- Limitations Physical;

- Bodily Pain;
Table 8 Group characteristics after propensity score matching for year 1

\begin{tabular}{|c|c|c|c|c|}
\hline \multirow[t]{2}{*}{ Characteristic } & \multicolumn{2}{|c|}{$\begin{array}{l}\text { Pre-matching } \\
\text { pooled }\end{array}$} & \multicolumn{2}{|c|}{$\begin{array}{l}\text { Post-matching } \\
\text { pooled }\end{array}$} \\
\hline & Rev & Cons & Rev & Cons \\
\hline \multicolumn{5}{|l|}{ Quality of life } \\
\hline SF-6D baseline & 0.65 & 0.71 & 0.66 & 0.67 \\
\hline EQ-5D baseline & 0.58 & 0.67 & 0.57 & 0.60 \\
\hline VAS baseline & 0.63 & 0.69 & 0.64 & 0.64 \\
\hline \multicolumn{5}{|l|}{ Demographics } \\
\hline Male gender (\%) & 67.14 & 63.52 & 65.48 & 67.33 \\
\hline Currently smoking (\%) & 58.57 & 50.82 & 58.24 & 57.95 \\
\hline Age $( \pm S D)$ & 63.97 & 66.53 & 64.76 & 64.44 \\
\hline Body mass index $( \pm S D)$ & 26.11 & 26.76 & 25.88 & 27.24 \\
\hline \multicolumn{5}{|l|}{ Disease severity } \\
\hline Fontaine I (\%) & 1.43 & 5.03 & 1.42 & 4.40 \\
\hline Fontaine IIa (\%) & 47.14 & 64.84 & 49.72 & 55.40 \\
\hline Fontaine IIb (\%) & 45.71 & 28.49 & 43.04 & 38.21 \\
\hline Fontaine III (\%) & 2.86 & 1.51 & 2.84 & 1.99 \\
\hline Fontaine IV (\%) & 2.86 & 0.13 & 2.98 & 0.00 \\
\hline Progressive symptoms (\%) & 74.29 & 40.25 & 71.45 & 75.00 \\
\hline Rest pain (\%) & 31.71 & 11.07 & 29.40 & 17.19 \\
\hline Complaints in daily life (\%) & 75.00 & 47.36 & 74.29 & 73.15 \\
\hline Claudication distance $<100 \mathrm{~m}(\%)$ & 45.29 & 18.36 & 42.61 & 44.89 \\
\hline Ankle brachial index $( \pm \mathrm{SD})$ & 0.70 & 0.73 & 0.70 & 0.71 \\
\hline \multicolumn{5}{|l|}{ Comorbidities } \\
\hline Stroke $(\%)$ & 17.14 & 10.69 & 17.61 & 16.48 \\
\hline Myocardial infarction (\%) & 7.14 & 14.47 & 7.95 & 9.23 \\
\hline No diabetes (\%) & 84.29 & 82.39 & 85.37 & 77.70 \\
\hline Untreated diabetes $(\%)$ & 1.43 & 2.52 & 1.42 & 8.66 \\
\hline Diabetes mellitus II (\%) & 14.29 & 10.69 & 13.21 & 9.52 \\
\hline Diabetes mellitus I (\%) & 0.00 & 4.40 & 0.00 & 4.12 \\
\hline Hypertension (\%) & 52.86 & 54.72 & 50.85 & 59.80 \\
\hline Cholesterol-lowering drug use (\%) & 84.29 & 81.13 & 84.23 & 79.83 \\
\hline Elevated D-Dimer (\%) & 32.86 & 30.82 & 32.53 & 30.82 \\
\hline Impaired kidney function (\%) & 12.86 & 24.53 & 13.78 & 14.06 \\
\hline Malignancies (\%) & 7.14 & 10.06 & 7.39 & 6.39 \\
\hline
\end{tabular}

Rev revascularised, Cons conservatively treated, $S D$ standard deviation

- Age;

- Myocardial infarction;

- Currently smoking. 


\section{Appendix 4: Scenario analyses}

See Tables 9, 10, 11, 12, 13, 14, 15, 16, 17 and 18.

\section{Year 1}

Table 9 Crude scores with propensity score matching, QoL change baseline to year 1

\begin{tabular}{llclc}
\hline & Rev crude score $(\mathrm{SE})$ & Cons crude score $(\mathrm{SE})$ & Mean difference $(\mathrm{SE})$ & $P$ value \\
\hline SF-6D & $0.042(0.022)$ & $-0.021(0.043)$ & $0.063(0.043)$ & 0.158 \\
EQ-5D & $0.089(0.047)$ & $0.026(0.050)$ & $0.064(0.071)$ & 0.377 \\
VAS & $0.023(0.054)$ & $0.018(0.059)$ & $0.005(0.082)$ & 0.951 \\
\hline
\end{tabular}

Rev revascularized, Cons conservative treatment

\section{Scenario 1: Unmatched sample}

Table 10 EMMs without propensity score matching, QoL change baseline to year 1

\begin{tabular}{|c|c|c|c|c|c|c|}
\hline & Rev EMM (SE) & Cons EMM (SE) & Mean difference (SE) & $P$ value & $R^{2}$ & $\overline{\text { Adjusted } R^{2}}$ \\
\hline SF-6D & $0.027(0.020)$ & $-0.004(0.012)$ & $0.031(0.022)$ & 0.155 & $0.176-0.228$ & $0.168-0.222$ \\
\hline EQ5D & $0.038(0.035)$ & $0.030(0.025)$ & $0.008(0.041)$ & 0.842 & $0.259-0.438$ & $0.252-0.433$ \\
\hline VAS & $0.003(0.045)$ & $0.013(0.020)$ & $-0.010(0.051)$ & 0.851 & $0.264-0.410$ & $0.257-0.405$ \\
\hline & \multicolumn{2}{|c|}{ Rev crude score (SE) } & Cons crude score (SE) & \multicolumn{2}{|c|}{ Mean difference (SE) } & $P$ value \\
\hline SF-6D & \multicolumn{2}{|c|}{$0.049(0.020)$} & $-0.013(0.014)$ & \multicolumn{2}{|c|}{$0.062(0.023)$} & 0.008 \\
\hline EQ-5D & \multicolumn{2}{|c|}{$0.090(0.046)$} & $0.008(0.026)$ & \multicolumn{2}{|c|}{$0.083(0.047)$} & 0.084 \\
\hline VAS & \multicolumn{2}{|c|}{$0.034(0.048)$} & $-0.001(0.025)$ & \multicolumn{2}{|c|}{$0.035(0.055)$} & 0.527 \\
\hline
\end{tabular}

$R^{2}$ are presented as ranges due to the presence of multiple imputation datasets

Rev revascularised, Cons conservative treatment, EMM estimated marginal mean

\section{Scenario 2: Unmatched sample, exclusively using patients} without cardiovascular events during follow-up

Table 11 EMMs without propensity score matching, QoL change baseline to year 1

\begin{tabular}{|c|c|c|c|c|c|c|}
\hline & Rev EMM (SE) & Cons EMM (SE) & Mean difference (SE) & $P$ value & $R^{2}$ & Adjusted $R^{2}$ \\
\hline SF-6D & $0.033(0.019)$ & $0.006(0.012)$ & $0.027(0.021)$ & 0.199 & $0.215-0.252$ & $0.207-0.244$ \\
\hline EQ-5D & $0.031(0.035)$ & $0.031(0.026)$ & $0.000(0.042)$ & 0.992 & $0.254-0.447$ & $0.247-0.442$ \\
\hline VAS & $0.006(0.046)$ & $0.027(0.020)$ & $-0.020(0.053)$ & 0.703 & $0.310-0.459$ & $0.304-0.454$ \\
\hline & \multicolumn{2}{|c|}{ Rev crude score (SE) } & Cons crude score (SE) & \multicolumn{2}{|c|}{ Mean difference (SE) } & $P$ value \\
\hline SF-6D & \multicolumn{2}{|c|}{$0.057(0.021)$} & $-0.004(0.013)$ & \multicolumn{2}{|c|}{$0.060(0.023)$} & 0.009 \\
\hline EQ-5D & \multicolumn{2}{|c|}{$0.087(0.048)$} & $0.008(0.027)$ & \multicolumn{2}{|c|}{$0.079(0.052)$} & 0.132 \\
\hline VAS & \multicolumn{2}{|c|}{$0.049(0.050)$} & $0.009(0.025)$ & \multicolumn{2}{|c|}{$0.041(0.056)$} & 0.477 \\
\hline
\end{tabular}

$R^{2}$ are presented as ranges due to the presence of multiple imputation datasets

Rev revascularised, Cons conservative treatment, EMM estimated marginal mean 


\section{Scenario 3: Unmatched sample, exclusively using complete} cases

Table 12 EMMs without propensity score matching, QoL change baseline to year 1

\begin{tabular}{lcccccc}
\hline & Rev EMM (SE) & Cons EMM (SE) & Mean difference (SE) & $P$ value & $R^{2}$ & Adjusted $R^{2}$ \\
\hline SF-6D & $0.052(0.023)$ & $0.021(0.016)$ & $0.031(0.029)$ & 0.274 & 0.102 & 0.084 \\
EQ-5D & $0.045(0.029)$ & $0.030(0.020)$ & $0.015(0.036)$ & 0.671 & 0.333 & 0.322 \\
VAS & $-0.010(0.027)$ & $0.003(0.019)$ & $-0.014(0.033)$ & 0.686 & 0.126 & 0.113 \\
\hline & Rev crude score (SE) & Cons crude score (SE) & Mean difference (SE) & $P$ value \\
\hline SF-6D & $0.066(0.026)$ & $0.015(0.015)$ & $0.042(0.025)$ & 0.073 \\
EQ-5D & $0.085(0.040)$ & $0.012(0.022)$ & $0.053(0.043)$ & 0.111 \\
VAS & $0.007(0.035)$ & $-0.005(0.018)$ & $0.009(0.031)$ & & 0.726 \\
\hline
\end{tabular}

$R^{2}$ are presented as ranges due to the presence of multiple imputation datasets

$R e v$ revascularised, Cons conservative treatment, EMM estimated marginal mean

\section{Scenario 4: Matched sample, excluding patients revascular-} ised in the second half of the first follow-up year

Table 13 EMMs with propensity score matching, QoL change baseline to year 1

\begin{tabular}{llccccc}
\hline & Rev EMM (SE) & Cons EMM (SE) & Mean difference (SE) & $P$ value & $R^{2}$ & Adjusted $R^{2}$ \\
\hline SF-6D & $0.015(0.025)$ & $-0.020(0.032)$ & $0.035(0.038)$ & 0.360 & $0.050-0.251$ & $0.026-0.231$ \\
EQ-5D & $0.077(0.043)$ & $0.013(0.060)$ & $0.064(0.077)$ & 0.416 & $0.354-0.499$ & $0.338-0.487$ \\
VAS & $0.027(0.036)$ & $-0.004(0.055)$ & $0.031(0.063)$ & 0.630 & $0.059-0.420$ & $0.035-0.405$ \\
\hline & Rev crude score (SE) & Cons crude score (SE) & Mean difference (SE) & $P$ value \\
\hline SF-6D & $0.018(0.026)$ & $-0.023(0.032)$ & $0.040(0.038)$ & 0.292 \\
EQ-5D & $0.083(0.054)$ & $0.007(0.068)$ & $0.076(0.092)$ & 0.417 \\
VAS & $0.037(0.054)$ & $-0.014(0.064)$ & $0.050(0.077)$ & 0.519 \\
\hline
\end{tabular}

$R^{2}$ are presented as ranges due to the presence of multiple imputation datasets

Rev revascularised, Cons conservative treatment, EMM estimated marginal mean

\section{Year 2}

Table 14 EMMs with propensity score matching, QoL change baseline to year 2

\begin{tabular}{llclc}
\hline & Rev crude score $(\mathrm{SE})$ & Cons crude score $(\mathrm{SE})$ & Mean difference $(\mathrm{SE})$ & $P$ value \\
\hline SF-6D & $0.018(0.026)$ & $-0.023(0.032)$ & $0.040(0.038)$ & 0.292 \\
EQ-5D & $0.083(0.054)$ & $0.007(0.068)$ & $0.076(0.092)$ & 0.417 \\
VAS & $0.037(0.054)$ & $-0.014(0.064)$ & $0.050(0.077)$ & 0.519 \\
\hline
\end{tabular}

Rev revascularised, Cons conservative treatment, EMM estimated marginal mean 


\section{Scenario 1: Unmatched sample}

Table 15 EMMs without propensity score matching, QoL change baseline to year 2

\begin{tabular}{|c|c|c|c|c|c|c|}
\hline & Rev EMM (SE) & Cons EMM (SE) & Mean difference (SE) & $P$ value & $R^{2}$ & $\overline{\text { Adjusted } R^{2}}$ \\
\hline SF-6D & $0.016(0.025)$ & $-0.035(0.016)$ & $0.050(0.030)$ & 0.093 & $0.078-0.108$ & $0.065-0.095$ \\
\hline EQ-5D & $0.068(0.038)$ & $0.011(0.023)$ & $0.057(0.044)$ & 0.198 & $0.301-0.435$ & $0.291-0.427$ \\
\hline VAS & $0.019(0.038)$ & $-0.015(0.026)$ & $0.034(0.045)$ & 0.448 & $0.164-0.307$ & $0.152-0.297$ \\
\hline & \multicolumn{2}{|c|}{ Rev rude score (SE) } & Cons crude score (SE) & \multicolumn{2}{|c|}{ Mean difference (SE) } & $P$ value \\
\hline SF-6D & \multicolumn{2}{|c|}{$0.051(0.020)$} & $-0.015(0.014)$ & \multicolumn{2}{|c|}{$0.067(0.025)$} & 0.007 \\
\hline EQ-5D & \multicolumn{2}{|c|}{$0.084(0.047)$} & $0.010(0.028)$ & \multicolumn{2}{|c|}{$0.074(0.049)$} & 0.136 \\
\hline VAS & \multicolumn{2}{|c|}{$0.040(0.046)$} & $-0.002(0.026)$ & \multicolumn{2}{|c|}{$0.042(0.053)$} & 0.433 \\
\hline
\end{tabular}

$R^{2}$ are presented as ranges due to the presence of multiple imputation datasets

$R e v$ revascularised, Cons conservative treatment, EMM estimated marginal mean

Scenario 2: Unmatched sample, exclusively using patients without cardiovascular events during follow-up

Table 16 EMMs without propensity score matching, QoL change baseline to year 2

\begin{tabular}{llrlrrr}
\hline & Rev EMM (SE) & Cons EMM (SE) & Mean difference (SE) & $P$ value & $R^{2}$ & Adjusted $R^{2}$ \\
\hline SF-6D & $0.021(0.025)$ & $-0.021(0.017)$ & $0.041(0.030)$ & 0.167 & $0.074-0.102$ & $0.058-0.087$ \\
EQ-5D & $0.062(0.043)$ & $0.015(0.024)$ & $0.048(0.049)$ & 0.327 & $0.304-0.452$ & $0.292-0.443$ \\
VAS & $0.021(0.041)$ & $-0.012(0.028)$ & $0.033(0.047)$ & 0.476 & $0.156-0.341$ & $0.141-0.330$ \\
\hline & Rev crude score (SE) & Cons crude score (SE) & Mean difference (SE) & $P$ value \\
\hline SF-6D & $0.055(0.022)$ & $0.000(0.014)$ & $0.055(0.025)$ & 0.031 \\
EQ-5D & $0.072(0.053)$ & $0.012(0.030)$ & $0.060(0.054)$ & 0.270 \\
VAS & $0.043(0.051)$ & $0.005(0.026)$ & $0.037(0.058)$ & 0.523 \\
\hline
\end{tabular}

$R^{2}$ are presented as ranges due to the presence of multiple imputation datasets

Rev revascularised, Cons conservative treatment, EMM estimated marginal mean

\section{Scenario 3: Unmatched sample, exclusively using complete}

\section{cases}

Table 17 EMMs without propensity score matching, QoL change baseline to year 2

\begin{tabular}{llccccc}
\hline & Rev EMM (SE) & Cons EMM (SE) & Mean difference (SE) & $P$ value & $R^{2}$ & Adjusted $R^{2}$ \\
\hline SF-6D & $0.001(0.033)$ & $0.011(0.021)$ & $-0.010(0.040)$ & 0.800 & 0.075 \\
EQ-5D & $0.031(0.033)$ & $0.038(0.023)$ & $-0.007(0.040)$ & 0.863 & 0.391 & 0.045 \\
VAS & $0.005(0.027)$ & $-0.011(0.021)$ & $0.016(0.035)$ & 0.643 & 0.060 & 0.036 \\
\hline & Rev crude score (SE) & Cons crude score (SE) & Mean difference (SE) & $P$ value \\
\hline SF-6D & $0.012(0.046)$ & $0.009(0.016)$ & $0.003(0.048)$ & 0.951 \\
EQ-5D & $0.059(0.048)$ & $0.028(0.025)$ & $0.031(0.054)$ & 0.563 \\
VAS & $0.010(0.032)$ & $-0.015(0.019)$ & $0.024(0.035)$ & 0.482 \\
\hline
\end{tabular}

$R^{2}$ are presented as ranges due to the presence of multiple imputation datasets

Rev revascularised, Cons conservative treatment, EMM estimated marginal mean 


\section{Scenario 4: Matched sample, excluding patients revascular- ised in the second half of the first follow-up year}

Table 18 EMMs with propensity score matching, QoL change baseline to year 2

\begin{tabular}{|c|c|c|c|c|c|c|}
\hline & Rev EMM (SE) & Cons EMM (SE) & Mean difference (SE) & $P$ value & $R^{2}$ & $\overline{\text { Adjusted } R^{2}}$ \\
\hline SF-6D & $0.015(0.025)$ & $-0.020(0.032)$ & $0.035(0.038)$ & 0.360 & $0.050-0.251$ & $0.026-0.231$ \\
\hline EQ-5D & $0.077(0.043)$ & $0.013(0.060)$ & $0.064(0.077)$ & 0.416 & $0.354-0.499$ & $0.338-0.487$ \\
\hline VAS & $0.027(0.036)$ & $-0.004(0.055)$ & $0.031(0.063)$ & 0.630 & $0.059-0.420$ & $0.035-0.405$ \\
\hline & \multicolumn{2}{|c|}{ Rev crude score (SE) } & Cons crude score (SE) & \multicolumn{2}{|c|}{ Mean difference (SE) } & $P$ value \\
\hline SF-6D & \multicolumn{2}{|c|}{$0.018(0.026)$} & $-0.023(0.032)$ & \multicolumn{2}{|c|}{$0.040(0.038)$} & 0.292 \\
\hline EQ-5D & \multicolumn{2}{|c|}{$0.083(0.054)$} & $0.007(0.068)$ & \multicolumn{2}{|c|}{$0.076(0.092)$} & 0.417 \\
\hline VAS & \multicolumn{2}{|c|}{$0.037(0.054)$} & $-0.014(0.064)$ & \multicolumn{2}{|c|}{$0.050(0.077)$} & 0.519 \\
\hline
\end{tabular}

$R^{2}$ are presented as ranges due to the presence of multiple imputation datasets

Rev revascularised, Cons conservative treatment, EMM estimated marginal mean

\section{References}

1. Hirsch, A. T., Criqui, M. H., Treat-Jacobson, D., et al. (2001). Peripheral arterial disease detection, awareness, and treatment in primary care. JAMA, 286(11), 1317-1324.

2. Norgren, L., Hiatt, W. R., Dormandy, J. A., Nehler, M. R., Harris, K. A., \& Fowkes, F. G. R. (2007). Inter-society consensus for the management of peripheral arterial disease (TASC II). Journal of Vascular Surgery, 45(1), 5-67.

3. Fowkes, F. G. R., Rudan, D., Rudan, I., Aboyans, V., Denenberg, J. O., McDermott, M. M., Norman, P. E., Sampson, U. K. A., Williams, L. J., Mensah, G. A., \& Criqui, M. H. (2013). Comparison of global estimates of prevalence and risk factors for peripheral artery disease in 2000 and 2010: a systematic review and analysis. Lancet, 382(9901), 1329-1340.

4. Aboyans, V., Ricco, J.-B., Bartelink, M.-L. E. L., Björck, M., Brodmann, M., Cohnert, T., Collet, J.-P., Czerny, M., De Carlo, M., Debus, S., Espinola-Klein, C., Kahan, T., Kownator, S., Mazzolai, L., Naylor, A. R., Roffi, M., Röther, J., Sprynger, M., Tendera, M., Tepe, G., Venermo, M., Vlachopoulos, C., \& Desormais, I. (2017). 2017 ESC Guidelines on the Diagnosis and Treatment of Peripheral Arterial Diseases, in collaboration with the European Society for Vascular Surgery (ESVS)Document covering atherosclerotic disease of extracranial carotid and vertebral, mesenteric, renal, upper and lower extremity arteriesEndorsed by: the European Stroke Organization (ESO)The Task Force for the Diagnosis and Treatment of Peripheral Arterial Diseases of the European Society of Cardiology (ESC) and of the European Society for Vascular Surgery (ESVS). Eur Heart J, ehx095-ehx095.

5. Breek, J. C., Hamming, J. F., De Vries, J., Aquarius, A. E., \& van B. Henegouwen, D. P (2001). Quality of life in patients with intermittent claudication using the World Health Organisation (WHO) questionnaire. European Journal of Vascular and Endovascular Surgery, 21(2), 118-122.

6. Nordanstig, J., Taft, C., Hensater, M., Perlander, A., Osterberg, K., \& Jivegard, L. (2014). Improved quality of life after 1 year with an invasive versus a noninvasive treatment strategy in claudicants: One-year results of the Invasive Revascularization or Not in Intermittent Claudication (IRONIC) Trial. Circulation, 130(12), 939-947.

7. Tendera, M., Aboyans, V., Bartelink, M.-L., Baumgartner, I., Clément, D., Collet, J.-P., Cremonesi, A., De Carlo, M., Erbel, R., Fowkes, F. G. R., Heras, M., Kownator, S., Minar, E., Ostergren,
J., Poldermans, D., Riambau, V., Roffi, M., Röther, J., Sievert, H., van Sambeek, M., Zeller, T., Bax, J., Auricchio, A., Baumgartner, H., Ceconi, C., Dean, V., Deaton, C., Fagard, R., Funck-Brentano, C., Hasdai, D., Hoes, A., Knuuti, J., Kolh, P., McDonagh, T., Moulin, C., Poldermans, D., Popescu, B., Reiner, Z., Sechtem, U., Sirnes, P. A., Torbicki, A., Vahanian, A., Windecker, S., Kolh, P., Torbicki, A., Agewall, S., Blinc, A., Bulvas, M., Cosentino, F., De Backer, T., Gottsäter, A., Gulba, D., Guzik, T. J., Jönsson, B., Késmárky, G., Kitsiou, A., Kuczmik, W., Larsen, M. L., Madaric, J., Mas, J.-L., McMurray, J. J. V., Micari, A., Mosseri, M., Müller, C., Naylor, R., Norrving, B., Oto, O., Pasierski, T., Plouin, P.-F., Ribichini, F., Ricco, J.-B., Ruilope, L., Schmid, J.-P., Schwehr, U., Sol, B. G. M., Sprynger, M., Tiefenbacher, C., Tsioufis, C., \& Van Damme, H. (2011). ESC Guidelines on the diagnosis and treatment of peripheral artery diseases. European Heart Journal 32(32), 2851-2906.

8. Reynolds, M. R., Apruzzese, P., Galper, B. Z., Murphy, T. P., Hirsch, A. T., Cutlip, D. E., Mohler, E. R., Regensteiner, J. G., \& Cohen, D. J. (2014). Cost-effectiveness of supervised exercise, stenting, and optimal medical care for claudication: Results from the Claudication: Exercise Versus Endoluminal Revascularization (CLEVER) trial. Journal of the American Heart Association, 3(6), $\mathrm{e} 001233$.

9. Wann-Hansson, C., Hallberg, I. R., Risberg, B., Lundell, A., \& Klevsgard, R. (2005). Health-related quality of life after revascularization for peripheral arterial occlusive disease: Long-term follow-up. Journal of Advanced Nursing, 51(3), 227-235.

10. Safley, D. M., House, J. A., Laster, S. B., Daniel, W. C., Spertus, J. A., \& Marso, S. P. (2007). Quantifying improvement in symptoms, functioning, and quality of life after peripheral endovascular revascularization. Circulation, 115(5), 569-575.

11. Vlajinac, H., Marinkovic, J., Tanaskovic, S., Kocev, N., Radak, D., Davidovic, D., \& Maksimovic, M. (2015). Quality of life after peripheral bypass surgery: A 1 year follow-up. Wiener klinische Wochenschrift, 127(5-6), 210-217.

12. De Wit, G. A., Busschbach, J. J. V., \& De Charro, F. T. (2000). Sensitivity and perspective in the valuation of health status: Whose values count? Health Economics, 9(2), 109-126.

13. Blieden, M., Smith, D., Becker, B. T., Paoli, C. J., \& Gandra, S. R. (2015). A systematic review of cardiovascular event utilities In Europe. Value in Health, 18(7), A397. 
14. Joore, M., Brunenberg, D., Nelemans, P., Wouters, E., Kuijpers, P., Honig, A., Willems, D., de Leeuw, P., Severens, J., \& Boonen, A. (2010). The impact of differences in EQ-5D and SF-6D utility scores on the acceptability of cost-utility ratios: results across five trial-based cost-utility studies. Value in Health, 13(2), 222-229.

15. Chetter, I. C., Spark, J. I., Dolan, P., Scott, D. J. A., \& Kester, R. C. (1997). Quality of life analysis in patients with chronic lower limb ischaemia: Suggestions for European standardisation. European Journal of Vascular and Endovascular Surgery, 13.

16. Mehta, T., Subramaniam, A. V., Chetter, I., \& McCollum, P. (2003). Disease-specific quality of life assessment in intermittent claudication: Review. European Journal of Vascular and Endovascular Surgery, 25(3), 202-208.

17. Klevsgård, R., Fröberg, B. L., Risberg, B., \& Hallberg, I. R. (2002). Nottingham Health Profile and Short Form 36 Health Survey questionnaire in patients with chronic lower limb ischaemia. Before and after revascularization. Journal of Vascular Surgery, 36.

18. Poku, E., Duncan, R., Keetharuth, A., Essat, M., Phillips, P., Woods, H. B., Palfreyman, S., Jones, G., Kaltenthaler, E., \& Michaels, J. (2016). Patient-reported outcome measures in patients with peripheral arterial disease: A systematic review of psycho metric properties. Health and Quality of Life Outcomes, $14,161$.

19. Dyer, M. T. D., Goldsmith, K. A., Sharples, L. S., \& Buxton, M. J. (2010). A review of health utilities using the EQ-5D in studies of cardiovascular disease. Health and Quality of Life Outcomes, $8,13-13$

20. Rooke, T. W., Hirsch, A. T., Misra, S., Sidawy, A. N., Beckman, J. A., Findeiss, L., Golzarian, J., Gornik, H. L., Jaff, M. R., Moneta, G. L., Olin, J. W., Stanley, J. C., White, C. J., White, J. V., \& Zierler, R. E. (2013). Management of patients with peripheral artery disease (compilation of 2005 and 2011 ACCF/AHA guideline recommendations): A report of the American College of Cardiology Foundation/American Heart Association Task Force on Practice Guidelines. Journal of the American College of Cardiology, 61(14), 1555-1570. F.

21. Hardman, R. L., Jazaeri, O., Yi, J., Smith, M., \& Gupta, R. (2014). Overview of classification systems in peripheral artery disease. Seminars in Interventional Radiology, 31(4), 378-388.

22. Rooke, T. W., Hirsch, A. T., Misra, S., Sidawy, A. N., Beckman, J. A., Findeiss, L. K., Golzarian, J., Gornik, H. L., Halperin, J. L., Jaff, M. R., Moneta, G. L., Olin, J. W., Stanley, J. C., White, C. J., White, J. V., Zierler, R. E., Society for Cardiovascular, A., \& Interventions (2011). 2011 ACCF/AHA focused update of the guideline for the management of patients with peripheral artery disease (updating the 2005 guideline): A report of the American College of Cardiology Foundation/American Heart Association Task Force on Practice Guidelines. Journal of the American College of Cardiology, 58(19), 2020-2045. S.

23. World Health Organization. (2000). Obesity: preventing and managing the global epidemic. Report of a WHO consultation. World Health Organization Technical Report Series, 894, i-xii, 1-253.

24. Romero, J.-M., Bover, J., Fite, J., Bellmunt, S., Dilmé, J.-F., Camacho, M., Vila, L., \& Escudero, J.-R. (2012). The modification of diet in renal disease 4-calculated glomerular filtration rate is a better prognostic factor of cardiovascular events than classical cardiovascular risk factors in patients with peripheral arterial disease. Journal of Vascular Surgery, 56(5), 1324-1330.

25. Aaronson, N. K., Muller, M., Cohen, P. D. A., Essink-Bot, M.-L., Fekkes, M., Sanderman, R., Sprangers, M. A. G., te Velde, A., \& Verrips, E. (1998). Translation, validation, and norming of the Dutch language version of the SF-36 health survey in community and chronic disease populations. Journal of Clinical Epidemiology, 51(11), 1055-1068.
26. Brazier, J., Roberts, J., \& Deverill, M. (2002). The estimation of a preference-based measure of health from the SF-36. Journal of Health Economics, 21(2), 271-292.

27. Lamers, L. M., Bouwmans, C. A. M., van Straten, A., Donker, M. C. H., \& Hakkaart, L. (2006). Comparison of EQ-5D and SF-6D utilities in mental health patients. Health Economics, 15(11), $1229-1236$

28. Zorginstituut Nederland. (2016). Guideline for economic evaluations in healthcare.

29. Lamers, L. M., McDonnell, J., Stalmeier, P. F. M., Krabbe, P. F. M., \& Busschbach, J. J. V. (2006). The Dutch tariff: Results and arguments for an effective design for national EQ-5D valuation studies. Health Economics, 15(10), 1121-1132.

30. EuroQol Group. (1990). EuroQol: A new facility for the measurement of health-related quality of life. Health Policy, 16(3), 199-208.

31. van Buuren, S. (2012). Flexible imputation of missing data. Boca Raton: CRC Press.

32. Allison, P. D. (2001). Missing data. New York: SAGE Publications.

33. Rosenbaum, P. R., \& Rubin, D. B. (1983). The central role of the propensity score in observational studies for causal effects. Biometrika, 70(1), 41-55.

34. Stuart, E. A. (2010). Matching methods for causal inference: A review and a look forward. Statistical Science, 25(1), 1-21.

35. Bland, J. M., \& Altman, D. G. (1995). Multiple significance tests: The Bonferroni method. BMJ, 310(6973), 170-170.

36. Vatcheva, K. P., Lee, M., McCormick, J. B., \& Rahbar, M. H. (2016). Multicollinearity in regression analyses conducted in epidemiologic studies. Epidemiology (Sunnyvale, Calif.), 6(2), 227.

37. Devine, E. B., Alfonso-Cristancho, R., Yanez, N., et al. (2016). Effectiveness of a medical vs revascularization intervention for intermittent leg claudication based on patient-reported outcomes. JAMA Surgery, 151(10), e162024.

38. Egberg, L., Mattiasson, A. C., Ljungstrom, K. G., \& Styrud, J. (2010). Health-related quality of life in patients with peripheral arterial disease undergoing percutaneous transluminal angioplasty: a prospective one-year follow-up. Journal of Vascular Nursing, 28(2), 72-77.

39. van Hattum, E. S., Tangelder, M. J., Lawson, J. A., Moll, F. L., \& Algra, A. (2011). The quality of life in patients after peripheral bypass surgery deteriorates at long-term follow-up. Journal of Vascular Surgery, 53(3), 643-650.

40. Holtzman, J., Caldwell, M., Walvatne, C., \& Kane, R. (1999). Long-term functional status and quality of life after lower extremity revascularization. Journal of Vascular Nursing, 29(3), 395-402.

41. McPherson, K., Myers, J., Taylor, W. J., McNaughton, H. K., \& Weatherall, M. (2004). Self-valuation and societal valuations of health state differ with disease severity in chronic and disabling conditions. Medical Care, 42(11), 1143-1151.

42. Versteegh, M. M., \& Brouwer, W. B. F. (2016). Patient and general public preferences for health states: A call to reconsider current guidelines. Social Science \& Medicine, 165, 66-74.

43. Brazier, J., Roberts, J., Tsuchiya, A., \& Busschbach, J. (2004). A comparison of the EQ-5D and SF-6D across seven patient groups. Health Economics, 13(9), 873-884.

44. Smolderen, K. G., van Zitteren, M., Jones, P. G., Spertus, J. A., Heyligers, J. M., Nooren, M. J., Vriens, P. W., \& Denollet, J. (2015). Long-term prognostic risk in lower extremity peripheral arterial disease as a function of the number of peripheral arterial lesions. Journal of the American Heart Association, 4(10), e001823.

45. Szende, Á, Svensson, K., Ståhl, E., Mészáros, Á, \& Berta, G. Y. (2004). Psychometric and utility-based measures of health status 
of asthmatic patients with different disease control level. PharmacoEconomics, 22(8), 537-547.

46. National Institute for Health and Care Excellence. (2017). Position statement on use of the EQ-5D-5L valuation set.

47. Dorian, P., Jung, W., Newman, D., Paquette, M., Wood, K., Ayers, G. M., Camm, J., Akhtar, M., \& Luderitz, B. (2000). The impairment of health-related quality of life in patients with intermittent atrial fibrillation: implications for the assessment of investigational therapy. Journal of the American College of Cardiology, 36(4), 1303-1309.

48. Suman-Horduna, I., Roy, D., Frasure-Smith, N., Talajic, M., Lespérance, F., Blondeau, L., Dorian, P., \& Khairy, P. (2013). Quality of life and functional capacity in patients with atrial fibrillation and congestive heart failure. Journal of the American College of Cardiology, 61(4), 455-460.

49. Jenkins, L. S., Brodsky, M., Schron, E., Chung, M., Rocco, T. J., Lader, E., Constantine, M., Sheppard, R., Holmes, D., Mateski, D., Floden, L., Prasun, M., Greene, H. L., \& Shemanski, L. (2005). Quality of life in atrial fibrillation: The Atrial Fibrillation
Follow-up Investigation of Rhythm Management (AFFIRM) study. American Heart Journal, 149(1), 112-120.

50. Altman, D. G., \& Bland, J. M. (1995). Absence of evidence is not evidence of absence. BMJ, 311(7003), 485-485.

51. Aboyans, V., Ricco, J. B., Bartelink, M. E. L., Bjorck, M., Brodmann, M., Cohnert, T., Collet, J. P., Czerny, M., De Carlo, M., Debus, S., Espinola-Klein, C., Kahan, T., Kownator, S., Mazzolai, L., Naylor, A. R., Roffi, M., Rother, J., Sprynger, M., Tendera, M., Tepe, G., Venermo, M., Vlachopoulos, C., \& Desormais, I. (2018). 2017 ESC Guidelines on the Diagnosis and Treatment of Peripheral Arterial Diseases, in collaboration with the European Society for Vascular Surgery (ESVS): Document covering atherosclerotic disease of extracranial carotid and vertebral, mesenteric, renal, upper and lower extremity arteries. European Heart Journal, 39(9), 763-816.

Publisher's Note Springer Nature remains neutral with regard to jurisdictional claims in published maps and institutional affiliations. 